Veröffentlichungen des Instituts für Österreichische Geschichtsforschung

Band 63

IOG

Böhlau Verlag Wien

\section{Urkunden - Schriften - Lebensordnungen}

Neue Beiträge zur Mediävistik

Vorträge der Jahrestagung des Instituts für Österreichische Geschichtsforschung aus Anlass des 100. Geburtstags von Heinrich Fichtenau (1912-2000)

(Wien, 13.-15. Dezember 2012)

Herausgegeben von

Andreas Schwarcz und Katharina Kaska

Böhlau Verlag Wien 


\title{
Emotionale Repertoires in religiösen Gemeinschaften des 13. Jahrhunderts
}

\author{
Eine Re-Lektüre von „Askese und Laster“
}

\section{Christina Lutter}

Bibliografische Information der Deutschen Nationalbibliothek: Die Deutsche Nationalbibliochek verzeichnet diese Publikation in der Deutschen Nationalbibliografie; detaillierte bibliografische Daten sind im Internet über http://portal.dnb.de abrufbar.

\section{Umschlagabbildung:}

Monogramm Karls des Großen, @ IÖ

(C) 2015 by Böhlau Verlag GmbH \& Co. KG, Wien Köln Weimar Wiesingerstraße 1, A-1010 Wien, www.boehlau-verlag.com

Alle Rechte vorbehalten. Dieses Werk ist urheberrechulich geschürzt. Jede Verwertung außerhalb der engen Grenzen des Urheberrechtsgeserzes ist unzulässig.

Satz: Bettina Waringer, Wien

Druck und Bindung: General,Szeged

Gedruckt auf chlor- und säurefreiem Papier Printed in the EU

ISBN 978-3-205-79633-6
Unter welchen Umständen darf der Historiker „Linien durch die Jahrhunderte“ ziehen, im Sinn von Großen oder Meta-Erzählungen, wie wir heute sagen würden, fragt Heinrich Fichtenau in der Vorbemerkung zu seinem programmatischen kleinen Buch mit dem Titel "Askese und Laster", das 1948 erschienen ist. Sofern die Auswertung der Quellen nicht einseitig entlang vorgegebener Kategorien erfolgt, lautet seine Antwort, dem Diktum Reinhard Kosellecks vom „Vetorecht" der Quellen vergleichbar. In beiden dem Text zugrunde liegenden Vorträgen zu den „historischen Wirkungen der christlichen Individualethik“, die der damals 34-jährige Fichtenau im März 1946 an der Wiener Katholischen Akademie gehalten hat, unternimmt er gleich mehrere Gänge durch die Jahrhunderte von der römischen Spätantike bis zur Reformation mit gelegentlich expliziten Ausblicken bis ins 19. Jahrhundert und in seine Gegenwart ${ }^{1}$. Sein ausdrückliches Interesse gilr dabei Fragen der menschlichen Psyche, denn auch wenn er mit Max Weber die grundsätzliche Vorsicht vor vereinfachender Anwendung psychologischer Begriffe auf die Geschichte teilt, dürfe, so Fichtenau, die „Sicht auf den Menschen als Ganzes" nicht verloren gehen. Im konkreten Fall geht es ihm zugleich um einen Ausgleich zwischen den wissenschaftstheoretischen Extremen des Rationalismus des 19. Jahrhundert und des "Vitalismus" eines Friedrich Nietzsche. Und hier sind wir schon mitten im Thema, bei den lebensweltlichen Bezügen zwischen Askese und Laster in mittelalterlichen Gemeinschaften: Askese versteht Fichtenau als „die historische Form der christlichen Ordnung und Steuerung der Affekre", die mittelalterliche Lehre von den Lastern als grundlegende

1 Fichtenau, Askese und Laster 7 [das Vorwort der Originalausgabe ist in der akruelleren Druckfassung des Textes in Fichrenau, Beiträge $124-107$, die auch einige inhaltliche Änderungen aufweist, nicht abgedruckt. Im Folgenden wird jeweils die Originalausgabe sowie, soweit möglich, die jeweilige Entsprechung in der aktuelleren Druckfassung in eckigen Klammern angegeben]; Reinhard KoseliEcK, Standortbindung und Zeitlichkeit. Ein Beitrag zur historiographischen Erschließung der geschichtlichen Welt [1977], in: Ders., Vergangene Zukunft. Zur Semantik geschichrlicher Zeiten (Frankfurt am Main 1989) 176-207, hier 206. Die Arbeiren zu diesem Text entstanden im Zusammenhang mit dem vom Österreichischen Wissenschaftsfonds (FWF) geförderten SFB 42 Visions of Community (VISCOM, Details vgl. http://www.univie.ac.at/viscom/index_viscom. php?seite=home, Zugriff am 29. 3. 2013), dessen Mitgliedern mein Dank für zahlreiche Anregungen und Kommentare zu diesem Text gilt, ebenso wie Karl Brunner, Philippe Buc, Stefan Erdei, Barbara Rosenwein und Horst Wenzel. - Abkürzungen: RB = Regula Benedicti; $\mathrm{DM}=$ Dialogus miraculorum. 
Richtschnur im Umgang mit ihnen - womit einige der für seine weiteren Ausführungen zentralen Begriffe benannt sind ${ }^{2}$.

Ich werde im ersten Teil meines Beitrags zunächst versuchen, in Form einer zusammenfassenden Re-Lektüre des Textes zentrale Thesen und Schlussfolgerungen von Fichtenaus Überlegungen herauszuarbeiten und dabei besonders auf die Rolle der Affekte bzw. Leidenschaften (passiones) in Fichtenaus theoretischen Konzeptionen Bezug nehmen. Im zweiten Teil möchte ich zeigen, warum die Konzepte der „emotional communities“ und der emotionalen Repertoires („emotional repertoires") geeignet sind, jene Thesen Fichtenaus zum historischen Wandel weiter zu denken, in denen er explizit Ambivalenzen und Widersprüche in den historischen Abläufen benennt. Sie liegen quer zu einer kausalen - und auch psychologisierenden - Entwicklungsgeschichte, die sein Text durchaus ebenso erzählt ${ }^{3}$. Dazu möchte ich mit dem Dialogus miraculorum des Caesarius von Heisterbach, der im ersten Viertel des 13. Jahrhunderts verfasst wurde, ein Beispiel praktisch orientierter pastoraler Theologie diskutieren, das im Schnittfeld einiger Aspekte einer der wichtigsten von Fichtenau identifizierten Übergangsphasen im Umgang mit kollektiven und individuellen religiösen Vorstellungen von Tugenden und Lastern und den entsprechenden asketischen Praktiken in monastischen Gemeinschaften steht ${ }^{4}$

Die für Fichtenau so zentrale „Sicht auf den Menschen als Ganzes“ wird gestützt von seinem Verständnis, dass das (früh-)mittelalterliche Christentum keine Trennung von "Religion und Sittlichkeit, religiösem ,Gefühlsleben " und ethisch-sozialer ,Werktätigkeit “" kenne. Diese Vorstellung einer Integration von Innen und Außen, von Mensch und Gesellschaft sowie des Aufeinander-Verwiesen-Seins spiritueller und sozialer Faktoren äußert sich grundlegend in der Konzeption der Gemeinschaft der Christen. Im Rahmen der ihr verpflichteten sozialen und moralischen Ständeordnung des europäischen Mittelalters wird der spirituelle Weg gemeinsam beschritten - die Stärkeren helfen den Schwächeren, Heilige den Sündern durch Gebet und durch ihre Verdienste ${ }^{5}$. Der Askese als Arbeit, als

2 Die beiden Zitate in Fichtenau, Askese und Laster 9f. [24] und 13 [27]. Fichtenau zitiert Max Weber, Die protestantische Ethik und der Geist des Kapitalismus, in: DERS., Gesammelte Aufsätze zur Religionssoziologie 1 (Tübingen 1934) 133 Anm. 1, sowie, bei aller weltanschaulichen Distanz, Friedrich NiETzsche, Wille zur Macht, in: DERS., Gesammelte Werke (Musarionausgabe 19, München 1926) 291, zu dessen Denken er hier eine explizite Verbindung herstellt die in dem gemeinsamen Interesse für die Steuerung der Affekte durch systematisches seelisches Training" bzw. "Gymnastik des Willens" besteht.

3 Vgl. Barbara H. Rosenwern, Emotional Communities in the Early Middle Ages (Ithaca 2006), sowie DIEs., Theories of Change in the History of Emotions, in: A History of Emotions 1200-1800, hg. von Jonas LILIEQUist (London 2012) 7-20. Zum Konzept der „emotional repertoires“ vgl. Christina LutTER, Preachers, Saints and Sinners. Emotional Repertoires in High Medieval Religious Role Models, in: ebd. 49-63. Zu Begriffen und Konzepten im Detail mit weiterführender Literatur unten S. 98 f.

4 Caesarius von Heisterbach, Dialogus miraculorum/Dialog über die Wunder, übersetzt und kommentiert von Nikolaus Nösges-Horst SChNeIder (Fontes Christiani 86/1-5, Turnhout 2009). Der lateinische Text folgt der Ausgabe Caesarii Heisterbacensis monachi ordinis Cisterciensis Dialogus miraculorum, ed. Joseph Strange (Köln 1851)

Das Zitat bei Fichtenau, Askese und Laster 14 [28]; ähnlich 34 [42]; eine Diskussion ebd., v. a. 18-20 [30-32], vgl. auch 29-31 [39f.]. Zur Konzeprion des Verhältnisses von „innen" und „außen" im Dialogus miraculorum, vgl. z. B. DM lib. 2, c. 1 (wie Anm. 4) 342-349, hier 348, zur Erläuterung der Arten der Reue: Interior est in amsarindine cordis, exterior in affictione corporis. Zur Reriprozirät spiricuellen und sozialen Ordnungsdenkens hier nur einige Grundlagenwerke: Arnold ANGENENDT, Geschichte der Religiositat im Mittelalter (Darmstadt ${ }^{4} 2009$ ); Fichtenau, Lebensordnungen; Otto Gerhard Oexie, Deutungsschemata der sozialen Wirklichkeit im Mittelalter, in: Mentalitäten im Mittelalter. Methodische und inhaltliche Probleme, hg. von František Graus (VuF 35, Sigmaringen 1987) 65-117; Klaus SCHreiner, Mönchsein in der Adelsgesellschaft des hohen und späten Mirtelaltrers. Klösterliche Gemeinschaftsformen zwischen spiritueller Selbstbehauptung
Methode und als Technik für diesen Weg nähert sich Fichtenau zunächst semantisch:

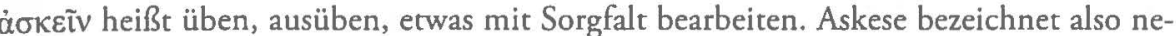
ben sportlichen oder militärischen Übungen (exercitia) ein spirituelles Handwerk, dessen Objekte Körper und Seele sind ${ }^{6}$. Körperliches und seelisch-geistiges Training sind aufeinander verwiesen. Bei Aristoteles und in der Stoa ist die Tugend als Folge freier Willensentscheidung im Handeln begründet ${ }^{7}$. Auch in den frühchristlichen Jahrhunderten wird die aktive asketische Betätigung als Willenstechnik und damit eine dauerhafte Haltung, einen Habitus, begründend gesehen. Askese, so Fichtenau, ist also eine Technik zur Kontrolle der Affekte durch den Willen, die im Dienst unterschiedlicher Weltanschauungen zur Anwendung kommen $\mathrm{kann}^{8}$. Gemeinsamer Ausgangspunkt ist aber jeweils das Bewusstsein einer inneren Unordnung, Störung oder Krankheit, die „außen“ sichtbar wird. Davon zeugen die zahlreichen Körper-Geist-Bezüge sowie die omnipräsente Körpermetaphorik in den Quellen ${ }^{9}$. An der Schnittstelle zwischen Körper und Geist kommen die Leidenschaften ins Spiel. Dabei sind die Haltungen zu den passiones ambivalent: Leidenschaften/ Affekte bringen zwar die Seele in Unordnung. Gelten die passiones aber stoischen Konzeptionen ebenso wie der Körper selbst überwiegend als grundsätzlich negativ, finden sich in christlichen Stellungnahmen ebenso Vorstellungen von den Tugenden als "geordneten" Leidenschaften ${ }^{10}$.

Warum aber, fragt Fichtenau, ist in mittelalterlichen Quellen so wenig von „der Läuterung und Entwicklung der Leidenschaften" die Rede, sondern vor allem vom Kampf gegen sie? Seine Antwort besteht zunächst in einem den Geschichtstheorien von Johan Huizinga, Norbert Elias und anderen vergleichbaren Narrativ, wonach das „im Gegensatz zu unserer heutigen Situation ... vitale Element im Menschen so stark [war], daß seine Bändigung zur Hauptaufgabe wurde, seine Pflege unnötig schien " ". Beherrscht werden

und sozialer Anpassung. $H Z 248$ (1989) 557-620, sowie die Beiträge in: Ordnungskonfigurationen im Hohen Mittelalter, hg. von Bernd Schneidmüller-Stefan Weinfurter (VuF 64, Sigmaringen 2006)

6 Fichtenau, Askese und Laster 19 [32]. Grundlegend ist Jean LeclercQ, Lamour des lettres er le désir de Dieu. Initiation aux auteurs monastiques du moyen âge (Paris 1957). Vgl. zusammenfassend DERs., Art. Askese, christliche. LMA 1 (1977) 1112-1115.

Richard SorabjI, Emotion and Peace of Mind: From Stoic Agitation to Christian Temptation (Oxford 2000); Simo KnuUtrila, Emotions in Ancient and Medieval Philosophy (Oxford 2004); vgl. auch den Beitrag von Barbara H. Rosenwein in diesem Band, S. $77 \mathrm{f}$

" Fichtenau, Askese und Laster 22f. [34]. Eine aktuelle Diskussion bieter Otto Gerhard Oexle, Koinos bios: Die Entstehung des Mönchtums, in: DERs., Die Wirklichkeir und das Wissen. Mitrelalterforschung Historische Kulturwissenschaft - Geschichte und Theorie der historischen Erkenntnis, hg. von Andrea voN HüLSEN-EsCH et al. (Göttingen 2011) 470-495; vgl. auch Albrecht DiEM, Das monastische Experiment. Die Rolle der Keuschheit bei der Entstehung des westlichen Kosterwesens (Vita regularis 36, Münster 2000).

9 Fichtenau, Askese und Laster 25 [37], nennt z. B. Adam von Bremen, Hamburgische Kirchengeschichte/Magistri Adam Bremensis gesta Hammaburgensis ecclesiae pontificum lib. III c. 63, ed. Bernhard SCHMEIDLER (MGH SS rer. Germ. in us. schol. [2], Hannover u. a. ${ }^{31917)}$ 209, als prominentes Beispiel für diese Wechselbezüge. Grundlegend sind die Arbeiten von Caroline W. Bynum, z. B: Art. Soul and Body. Dictionary of the Middle Ages, Supplement (2004) 588-594, und aktuell dres., Christian Materiality. An Essay on Religion in Late Medieval Europe (New York 2011). Vgl. unten Anm. 16-18.

io Zur Ambivalenz der passiones vgl. z. B. SoraBji, Emotion (wie Anm. 7); Rosenwein, Emotional Communities (wie Anm. 3); zu ihrer Schnitrstellenfunktion im Zusammenhang mit der Kategorie Geschlecht vgl. Christina Lutrer, Geschlechr, Gefühl, Körper - Karegorien einer kulturwissenschaftlichen Mediäviscik?. L'Homme. Europäische Zeitschrift für feministische Geschichtswissenschaft 18/2 (2007) 9-26.

Die Zitate: Fichtenau, Askese und Laster 28 [38]. Norbert Elias, Über den Prozeß der Zivilisation, 2 Bde. (Frankfurt am Main 2002), erstmals Basel 1939, hat Fichtenau 1946/48 vermutlich noch nicht rezipiert, jedenfalls zitiert er ihn nie. Johan HuIZINGA, Herbst des Mittelalters. Studien über Lebens- und Geistesformen 
können die Leidenschaften mit Augustinus jedenfalls nur mit Hilfe Gottes, der über die Menschen gebietet, wie diese es über ihre Leidenschaften tun sollen. Ziel ist, die Orientierung des menschlichen Willens auf sich selbst durch jene auf Gott zu ersetzen. Askese als reinigende Affektsteuerung führt aus der Krankheit zur Gesundheit, von der Unordnung bzw. Perversion im Sinn der Abwendung von Gott und Hinwendung zur Welt zu einer Wiederherstellung der gottgewollten Ordnung und dementsprechend zur "geordneten und maßvollen Leidenschaft der Seele", wie es Richard von St. Victor formuliert ${ }^{12}$. Für den geistlichen Stand wird mit der Entscheidung für ein der Welt abgewandtes Leben die „innere Schulung" zur Hauptaufgabe geistlicher Menschen, disciplina konstituiert ordo ${ }^{13}$. Die abendländische monastische Askese meint einen Lebensstil in seiner Gesamtheit. Askese ist Handeln, innere Haltung und äußere Darstellung. In der Benediktregel werden die zwölf Grade der Demut mit Übungen der praktischen Askese verbunden, die von der Gottesfurcht zur Gottesliebe führen sollen (c. 7).

Bis ins 11. Jahrhundert strukturiert das ständische Modell der göttlichen Weltordnung Ordnungsvorstellungen und -konfigurationen ${ }^{14}$. Je höher Rang und Stand, umso mehr wird verlangt: vom Christen mehr als von Nicht-Christen, von geistlichen Menschen und Amtsträgern mehr als von Weltlichen. Es gilt, „die Aufgaben dieses Daseins in der Gemeinschaft des Standes zu lösen, auch die der Askese" ${ }^{\text {"15. }}$. Diese integrative Weltsicht, so lautet Fichtenaus These, beginnt mit dem 11. Jahrhundert zu schwinden, „unter der Hülle von Tradition und Konvention beginnt ein Rückzug des Menschen auf sich selbst". Fichtenaus Kronzeuge für den Beginn dieses Phänomens ist der Libellus de suis tentationibus des Otloh von St. Emmeram, der das Auseinanderklaffen von innerer Haltung und äußerer Darstellung problematisiert ${ }^{16}$. Neu sei die nahezu wissenschaftlich kri-

des 14. und 15. Jahrhunderts in Frankreich und in den Niederlanden (Stuttgart ${ }^{12} 2006$ ), zitiert er öfters, z. B. 60 Anm. 145 [61 Anm. 143] oder 121 Anm. 188 [105 Anm. 185], jeweils in der 5. Auflage von 1939 [7. Auf. 1953].

12 Fichtenau, Askese und Laster 29-33 [38-41], das Zitat 33 [41]. Bei Richard von St. Victor, Beniamin minor, c. 7, heißt es wörtlich: Siquidem, nichil aliud est virtus quam animi affectus ordinatus et moderatus. (Richard de Saint-Victor, Les Douze Patriarches ou Beniamin minor, ed. et trad. Jean CHÂTILloN-M. Duchet-Suchaux [SC 419, Paris 1997] 108-111, hier 108). Ähnlich auch Bernhard von Clairvaux, Sermones super Cantica Canticorum, Sermo 34, 3: De humilitate voluntaria, wo es in diesem Sinn um die Übereinstimmung des menschlichen Willens mit jenem Gottes geht (Bernhard von Clairvaux, Sämtliche Werke lateinisch/ deutsch, Bd. 5 [Innsbruck 1994] 538-544). Zu Bernhards grundsäzalicher Auseinandersetzung mit c. 7 De bumilitate der Benediktregel, ed. Rudolf HansLIK (CSEL 75, Wien 1960) zitiert nach der online-Version: http:// www.thelatinlibrary.com/benedict.html (letzter Zugriff am 25. 3. 2013) in seinem Liber de gradibus bumilitatis et superbiae siehe unten Anm. 62 (vgl. auch Anm. 60). Zu Begriff und Prinzip der Reinigung in der mittelalterlichen Lasterlehre aus differenzierter anthropologischer Perspektive: Richard NewHAUSER, The Capital Vices as Medieval Anthropology, in: Laster im Mittelalter/Vices in the Middle Ages, hg. von Christoph FlüELER-Martin RoHDE (Scrinium Friburgense 23, Berlin u. a. 2009) 105-123, besonders 108f. und 117.

13 Vgl. die Zusammenfassung und Diskussion bei Hans-Jürgen Derda, Vita communis. Studien zur Geschichte einer Lebensform in Mittelalter und Neuzeit (Köln u. a. 1992), sowie OExLE, Koinos bios (wie Anm. 8).

14 Wie Anm. 5. Vgl. außerdem die Beiträge in Schneidmüller-Weinfurter, Ordnungskonfigurationen (wie Anm. 5), und in: Religiöse Ordnungsvorstellungen und Frömmigkeitspraxis im Hoch- und Spätmittelalter, hg. von Jörg RoGGe (Korb 2008).

15 Fichtenau, Askese und Laster 43 [49].

16 Das Zitat ebd. 47; Otloh von St. Emmeram, Libellus de suis tentationibus, varia fortuna et scriptis, PL 146 28-58, hier 32. Zu Otloh vgl. auch Hedwig Röckelein, Otloh, Gottschalk, Tnugdal: Individuelle und kollektive Visionsmuster des Hochmittelalters (Frankfurt am Main 1987). Zur grundsätzlichen Problematik vgl. Thomas LENTEs, Andacht und Gebärde. Das religiöseAusdrucksverhalten, in: Kulturelle Reformation. Sinnformationen im Umbruch (1400-1600), hg. von Bernhard Jussen-Craig KosLofsky (Veröffendlichungen tische Haltung Otlohs gegenüber dem Beispiel von Autoritäten, das man früher selbstverständlich nicht in Frage gestellt habe. Neu seien zudem die Thematisierung des eigenen Selbst und die inneren Auseinandersetzungen, die „minutiöse Seelenschilderung“, welche die „geistige Gemeinsamkeit des Konvents“ durchbricht ${ }^{17}$. Mit diesem neuen „subjektiven Frömmigkeitsstil“" weiche die einfache Klarheit des Weltbildes, „die naive Einheit von Gott, Welt und Psyche" einem komplizierten „Zusammenspiel von Verstand, Wille und Gefühl". Allerdings - und hier werden wieder Ambivalenz und Gleichzeitigkeit betont wechselt die „Gesamtheit der psychischen Entwicklung“ zwischen „Zeiten der kindlichen Weltoffenheit" und „solchen anscheinender Zerrüttung des Gefüges" ${ }^{18}$.

Auch die Beziehung von Mensch zu Gott werde nun individueller konzipiert, als eine zwischen Ich und Du, Braut und Bräutigam: Der Schlüssel-Affekt ist die Liebe zu Gott und dem Nächsten ${ }^{19}$. Sie sei zwar sehr wohl in den „alten sozialen Gemeinschaftsformen“ verankert. Dennoch: Trotz Berufung auf die Benediktregel gelte die Unbedingtheit der inneren und äußeren Gemeinsamkeit nicht mehr. Gemeinsame asketische Übung wird durch individuelle mystische imitatio Christi ersetzt, und darin auch Körper und Leiblichkeit aufgewertet ${ }^{20}$. Die Wende vom Gemeinschaftserlebnis des Göttlichen zu einer

des Max-Planck-Institures für Geschichte 145, Görtingen 1998) 29-67, und Rüdiger ScHNELL, Wer sieht das Unsichtbare? Homo exterior und homo interior in monastischen und laikalen Erziehungsschriften, in: „anima“ und ${ }_{n}$ sêle". Darstellungen und Systematisierungen von Seele im Mittelalter, hg. von Katharina PHILIPowskiAnne Prior (Philologische Studien und Quellen 197, Berlin 2006) 83-112, sowie demnächst Mirko BrerteNsTEIN, Das „Haus des Gewissens“. Zur Konstruktion und Bedeutung innerer Räume im Religiosentum des Hohen Mittelalters, in: Geist und Gestalt. Monastische Raumkonzepte als Ausdrucksformen religiöser Leitideen, hg. von Gert Melville-Jörg SonNtag (Vita regularis. Abhandlungen, Berlin 2014) [in Druckvorbereitung].

17 Fichtenau, Askese und Laster 45 [50].

18 Die Zitate ebd. 46-48 [51f.; einige der wörtlichen Zitate finden sich nur in der Originalausgabe] Diese These wurde v. a. seit den 1980er Jahren mit der Frage nach der "Entdeckung des Individuums" kritisch diskutiert, exemplarisch Caroline W. Bynum, Did the Twelfth Century Discover the Individual?, in: DIEs., Jesus as Mother: Studies in the Spirituality of the High Middle Ages (Berkeley 1982) 82-109; und DIEs.-Susan R. Kramer, Revisiting the Twelfth-Century Individual. The Inner Self and the Christian Community, in: Das Eigene und das Ganze. Zum Individuellen im mittelalterlichen Religiosentum, hg. von Gert MelvileE-Markus Schürer (Vita regularis 16, Münster 2002), sowie die Beiträge in: Individuum und Individualität im Mittelalter, hg. von Jan A. AerTsen-Andreas Speer (Miscellanea mediaevalia 24, Berlin-New York 1996); Unverwechselbarkeit. Persönliche Identität und Identifikation in der vormodernen Gesellschaft, hg. von Peter voN Moos (Norm und Struktur 23, Köln u. a. 2004); Frömmigkeit im Mittelalter. Politisch-soziale Kontexte, visuelle Praxis, körperliche Ausdrucksformen, hg. von Klaus Schreiner (München 2002). Einen integrativen Ansatz vertritt Fichtenau am Ende seines Buches (Askese und Laster 119) auch selbst: ${ }_{\text {}}$ So wie der Mensch Christus nachahmen muß, um zur individuellen Erlösung zu gelangen, muß er auch die demütige Einordnung am angewiesenen Platz in der großen Ordnung selbst vollziehen." [103, allerdings ebenfalls mit leicht verändertem Wortlaut].

19 Eine Auswahl aus der aktuellen Literatur zu diesem Thema: Damien Boquet, L'ordre de l'affect au Moyen Âtge. Autour de l'anthropologie affective d'Aelred de Rievaulx (Caen 2005); Brian P. McGuire, Friendship and Communiry. The Monastic Experience, 350-1250 (Ithaca ${ }^{2} 2010$ ); Rosenwein, Theories of Change (wie Anm. 3), bes. 15-18.

20 Fichtenau, Askese und Laster 47-50 [51-54]. Dazu sehr differenziert etwa Caroline W. Bynum, The Cistercian Conception of Community, in: DIEs., Jesus as Mother (wie Anm. 18) 59-81; vgl. außerdem SCHreINER, Frömmigkeit (wie Anm. 18); spezifischer Urban KüsTers, Der verschlossene Garten. Volkssprachliche Hohelied-Auslegung und monastische Lebensform im 12. Jahrhundert (Düsseldorf 1985), und den Kommentar von Friedrich Ohly zu Das St. Trudperter Hohelied. Eine Lehre der liebenden Gotteserkenntnis, ed. und übersetzt von Friedrich OHLY unter Mitarbeit von Nicola KLEINE (Frankfurt am Main 1998); Zur Mystik exemplarisch: Peter DinzelbaCher, Deutsche und niederländische Mystik des Mittelalters (Berlin 2012); Kurt RuH, Geschichte der abendländischen Mystik. Die Grundlegung durch die Kirchenväter und die Mönchstheologie des 12. Jahrhunderts (München 22001). 
Ich-Du-Beziehung zu Christus hatte mit Fichtenau maßgebliche Auswirkungen auf das Ständemodell: Waren die Stände früher klar entlang ihrer geistlichen und weltlichen Aufgabenbereiche getrennt, so konnten durch religiöse Reform- und Laienbewegungen auch Weltliche den unmittelbaren Weg zu Gott suchen, konnte das mystische Erlebnis den "mühevollen und schwierigen Weg der Reinigung durch die Askese ersetzen". In diesen neuen Formen subjektiven religiösen Erlebens sieht Fichtenau gleichzeitig die Infragestellung alter Ordnungsvorstellungen begründet ${ }^{21}$.

Diese Überlappung geistlicher und weltlicher Standesideale, der Wandel monastischer Lebensformen in Wechselwirkung mit gesellschaftlichen Veränderungen, lässt sich aber bereits viel früher ausmachen, wie Fichtenau selbst in seinen Ausführungen zur christlichen Lasterlehre im zweiten Teil seines Buchs deurlich macht. Seit der Spätantike wurde militärische Disziplin sowohl terminologisch wie praktisch ein wesentlicher Teil monastischer Organisationskultur ${ }^{22}$. Die Idee der Unterordnung als Glied in der Gemeinschaft, als Teil des Ganzen sei zentral für das feudale europäische Mittelalter ebenso wie die Figur des miles Christi und die Aufgabe der militia Christi ${ }^{23}$. Damit korrespondierend entwickelt sich sowohl die Vorstellung der Weltgeschichte als Kampf - zwischen Christus und Satan, Engeln und Heiligen gegen Teufel und Dämonen, Tugenden gegen Laster im Inneren der Seele - als auch jene einer Wechselwirkung geistlicher und weltlicher Standesideale. Personalisierte Kampfmetaphorik verweist auf die gesellschaftlichen Prinzipien von Gefolgschaft und Treue - wieder sehen wir eine Verknüpfung sozialer und spiritueller Prinzipien ${ }^{24}$. Im Kampf zwischen Christus und dem Satan spielt dementsprechend das Bild der Heerführer eine besondere Rolle, wie auch der Kriegsdienst mit den Waffen des Gehorsams in der Benediktregel. Dabei hängt es von den zeitbedingten Vorstellungen ab, ob man sich diesen Kampf eher als einen mit personalisierten Dämonen oder mit Lastern innerhalb des Menschen vorstelle. Jedenfalls müssen göttliche Gnade und eigene Leistung zusammenwirken, die Seele wird „zum Schnittpunkt des göttlichen Bereichs mit dem teuflischen" 25 .

21 Fichtenau, Askese und Laster 51 [55]. Später ausführlich in DERs., Lebensordnungen, und DERS., Ketzer und Professoren. Zu den religiösen Reformbewegungen des 11.-13. Jahrhunderts grundlegend Giles CONSTABLE, The Reformation of the Twelfth Century (Cambridge 1996), und DERs., Religious Communities, 1024-1215, in: The New Cambridge Medieval History, hg. von David LuscombE-Jonathan R R LEY-SMITH (Cambridge 2004) 335-367; Stefan WErnfurTer, Die Macht der Reformidee. Ihre Wirkkraft in Ritualen, Politik und Moral der spätsalischen Zeir, in: Religiöse Ordnungsvorstellungen (wie Anm. 14) 13-39; Innovation in Klöstern und Orden des Hohen Mittelalters. Aspekte und Pragmatik eines Begriffs, hg. von Mirko BrerrenSTEIN et al. (Vita regularis 48, Münster 2013).

22 Fichtenau, Askese und Laster 67-75 [65-71] mit dem wichtigen Zusatz, kriegerische Bilder würden
. durch die Zunahme militärischer Elemente allerdings nur gefördert, nicht begründer; vgl. dazu DerDa, Vita communis (wie Anm. 13), und OexLe, Koinos bios (wie Anm. 8).

23 Grundlegend ist Thomas Zotz, Milites Christi: Ministerialität als Träger der Kanonikerreform, in: Reformidee und Reformpolitik im spätsalisch-frühstaufischen Reich, hg. von Stefan WEINFURTER-Hubertus SeIBERT (Quellen und Abhandlungen zur Mittelrheinischen Kirchengeschichte 68, Mainz 1992) 301-328. SEIBERT (Quellen und Abhandlungen zur Mittelrheinischen Kirchengeschichte 68, Mainz 1992) 301-328.
Vgl. Katherine Allen SmITH, War and the Making of Medieval Monastic Culture (Woodbridge, UK-Rochester, NY, 2011).

${ }_{24}$ Fichtenau, Askese und Laster 78f. [73f.], mit zahlreichen Beispielen. Zur standes- und geschlechterübergreifenden Metaphorik von hochmittelalterlichen Darstellungen der militia Christi vgl. etwa Horst WENzEL, Bilder für den Hof. Zeitlichkeit und Visualisierung in den illustrierten Handschriften des Welschen Gastes von Thomasin von Zerclaere, in: Geschichtsdarstellung. Medien - Methoden - Strategien, hg. von Vittoria Borsò-Christoph KANN (Köln u. a. 2004) 193-213, bes. 206; Christina LuTrer, Zwischen Hof und Kloster. Borsò-Christoph KanN (Köln u. a. 2004) 193-213, bes. 206; Christina LuTr
Kulturelle Gemeinschaften im mittelalterlichen Österreich (Wien 2010) 11-48.

${ }_{25}$ Fichtenau, Askese und Laster 79 [74]; bei Gregor dem Großen heißt es: Temperantia quippe uitia,
So treten in der enorm einflussreichen Psychomachia des spätantiken Dichters Prudentius die innerseelischen, aber personifizierten Tugenden gegen die Laster zum allegorischen Kampf an. Auch wenn Fichtenaus Sympathien für dieses populäre „Handbuch der Moralpsychologie fürs Volk" begrenzt sind, gesteht er ihm als dem „erste[n] und bedeutendste[n] allegorischen Gedicht des christlichen Altertums" zu, abstrakte Begriffe durch greifbare lebendige Gestalten und dramatische Szenen zu ersetzen und so auch die einfachen Menschen zu erreichen, was seine außerordentliche Rezeption begründet habe $^{26}$. Gleichzeitig äußert sich Fichtenau an dieser Stelle explizit kritisch zu einer fachdisziplinär trennenden Wissenschaftstradition, die sich auf die Untersuchung gelehrter Tradition beschränke und der Frage nach der lebensweltlichen Relevanz theologischer Inhalte für die Menschen ausweiche. Pointiert: Prudentius' „Gedicht ... half mehr zur inneren Formung als die theologische Summa eines Thomas von Aquin". Der Kampf aller Menschen, Geistlicher und Weltlicher, gegen die Laster sei eine geistesgeschichtliche Fragestellung, die sich nicht „auf Systeme und Theoreme beschränkt, sondern tief hinabführt in das konkrete seelische Sein des Menschen der Vergangenheit"27.

Die bekannte Idee der militia Christi jedenfalls wurde zum zentralen Bestandteil der neuen Frömmigkeit in Nachfolge Christi, sowohl der hochmittelalterlichen Laienbewegung wie auch der geistlichen Ritterschaft der Kreuzzugsbewegung. Es kommt zu einer "Spiritualisierung des weltlichen Kriegertums" ebenso wie der Standesideale ${ }^{28}$. Diese erneute Integration geistlicher und weltlicher Bereiche erzeugte gleichzeitig eine Reihe von Widersprüchen und wurde daher bereits von Zeitgenossen als Verkehrung der gottgewollten Ordnung kritisiert, denn die „Erfordernisse [des monastischen] Standes" benötigen den „fein durchgebildete[n] Apparat der ständigen Leistungskontrolle, ohne den Asketik nicht möglich war". Doch auch in diesem Punkt stellt Fichtenau umgehend eine vergleichbare Entwicklung im ritterlichen bzw. höfischen Habitus fest: Auch die Ideale der mâze und staete bedeuten eine Bändigung der Gefühle und Akzeptanz der ständischen Ordnung ${ }^{29}$. Fichtenau sieht den Grund für diese Parallelität geistlicher und welt-

quae inuisibili contra nos proelio regnanti super se superbiae militant, alia more ducum praeeunt, alia more exercitus subsequuntur. (Moralia in Iob lib. 31, c. 45, 87, ed. Markus Adriaen [CCSL 143, 143A, 143B, Turnhout 1979-1985] 1610). Dazu Newhauser, Vices as Anthropology (wie Anm. 12) 113f;; in der RB (wie Anm. 12) c. 58: Ecce lex sub qua militare vis; si potes observare, ingredere; si vero non potes, liber discede.

26 Clemens Aurelius Prudentius, Psychomachia, Die Psychomachie des Prudentius, lat.-dt. von Ursmar Engrimann (Basel-Wien 1959) nach der Edition von Johannes Bergman (CSEL 61, Wien-Leipzig 1926); dazu S. Georgia Nugent, Allegory and Poetics. The Structure and Imagery of Prudentius' "Psychomachia“ (Studien zur klassischen Philologie 14, Frankfurt am Main-Bern 1985); Joanne S. Norman, Metamorphoses of an Allegory. The Iconography of the Psychomachia in Medieval Art (New York u. a.1988); mit einem Úberblick über die rezente Forschungsliteratur: Sabine GreBE, The End Justifies the Means. The Role of Deceit in Prudentius' "Psychomachia“, in: Laster im Mittelalter (wie Anm. 12) 11-43.

27 Fichtenau, Askese und Laster 87 [80] und 93 [dieses Zitat finder sich ausschließlich in der Originalausgabe von 1948]. Diese Problematik ist immer noch aktuell, und sie war es bereirs im 12/13. Jahrhundert, als es in den scholastischen Schulen zu einer zunehmend theoretischen und der spirituellen Praxis fernen Beschäftigung mit den Fragen von Tugenden und Lastern kam, vgl. etwa Newhiuser, Vices as Anthropology (wie Anm. 12) $109 f$. Die Wechselwirkung dieser Diskurse betont z. B. Bynum, Christian Materiality (wie Anm. 9) 129.

28 Fichtenau, Askese und Laster 70 und 72 [68f.]; dazu Weinfurter, Reformidee (wie Anm. 21); Zotz, Milites Christi (wie Anm. 23); vg!. auch unten Anm. 61.

29 Fichtenav, Askese und Laster 71 [70]. Grundlegend sind Joachim Bumke, Höfische Kultur, Literatur und Gesellschaft im hohen Mittelalter (München "2005); C. Stephen JAEGER, The Origins of Courtliness. Civilizing Trends and the Formation of Courtly Ideals, 939-1210 (Philadelphia 1985); Horst WENzeL, Hören und Sehen, Schrift und Bild: Kultur und Gedächtnis im Mittelalter (München 1995). Vgl. Karl BrunNer, Kleine Kulturgeschichte des Mittelalters (München 2012). 
licher Phänomene - trotz der angesprochenen Ungleichzeitigkeiten - abermals in einem „Verlust der alten Selbstverständlichkeiten und Unmittelbarkeit, dem der Gewinn rationaler Schärfe und Klarheit und eine fein ausgewogene Ästhetik auch im Gefühlhaften gegenübersteht “30. Das Prinzip des Maßhaltens ist aber bereits eine in der Benediktregel paradigmatisch festgeschriebene Grundtugend. Warnungen vor geistlichem Extremismus, etwa bei Thomas von Aquin, seien daher nicht neu, sondern ein Grundproblem der „Balance" der asketischen Praxis und der gelehrten wie der praktisch pastoralen Theologie ${ }^{31}$.

Genau diese Frage des richtigen Maßes bzw. der emotionalen Balance bietet Anknüpfungspunkte für eine Geschichte der Emotionen ebenso wie für eine Kulturgeschichte von Gemeinschaftsvorstellungen: Denn Fichtenau interpretiert Askese als historische, also zeitgebundene Form christlichen Ordnungsdenkens und Technik der Affektkontrolle, als Arbeit an Körper und Geist in geistlichen Gemeinschaften; und er liest die mittelalterliche Lehre von den Lastern als innere Richtschnur besonders für Angehörige des geistlichen Standes, aber darüber hinaus als praktisch-didaktisches Instrument auch gegenüber einem weltlichen Publikum im Rahmen eines christlichen Motivationshorizonts ${ }^{32}$.

Ein "Übersetzungsproblem", das sich aus der von Fichtenau selbst zu Beginn angesprochenen Kontextgebundenheit jeder Beschäftigung mit Geschichte ergibt, besteht allerdings darin, dass sein Werk zwei unterschiedliche Narrative zugleich anbietet: Einerseits ist es - und das ist zeittypisch - trotz des Weber'schen caveat zu Beginn einem stark psychologisierenden Ansatz verpflichtet. Historischer Wandel wird im Sinn des klassischen zivilisationstheoretischen Narrativs als grundsärzlich kollekriv gedachte Veränderung des Menschen an sich im Sinn der Abfolge der Lebensalter interpretiert. Dieses Modell des Zivilisationsprozesses, welches das menschliche Gefühlsleben in Form einer Entwicklung von kindlicher Einfachheit, Unmittelbarkeit und Impulsivität zu sukzessive verfeinerten, differenzierten und vielfältigen Formen des emotionalen Ausdrucks auffasste, wurde in den vergangenen Jahrzehnten vielfach kritisiert, zuletzt aus emotionsgeschichtlicher Perspektive von Barbara Rosenwein ${ }^{33}$. Andererseits unterstreicht Fichtenau selbst mit seiner quellennahen Interpretation der von ihm vorgestellten Phänomene immer wieder deren Gleichzeitigkeit und Ambivalenz, ja sogar Widersprüchlichkeit, die sich nicht leicht in das Narrativ einer eindeutigen Entwicklungsgeschichte historischen Wandels einpassen lassen.

Hier scheint mir ein Ansatz hilfreich, der statt einer großen Erzählung kollektiver psychischer Entwicklungen Emotionen historisiert und als kulturelle Repräsentationen auffasst ${ }^{34}$. Heute wissen wir, dass wir historisch ebenso wenig wie gegenwärtig direkt

30 FichTENAU, Askese und Laster 72 [69]. Disziplinenübergreifend verweist er auch auf die Vergleichbarkeit hochmittelalterlicher höfischer Dichtung und geistlicher mystischer Einfühlung. Aktuell z. B. die Beiträge in: Dichtung und Didaxe. Lehrhaftes Sprechen in der deutschen Literatur des Mittelalters, hg, von Henrike LäHNEMANN (Berlin u. a. 2009).

31 Fichtenau, Askese und Laster 73 [70]. Vgl. Robert Miner, Thomas Aquinas on the Passions. A Study of Summa Theologiae la2ae 22-48 (Cambridge 2009).

${ }_{32} \mathrm{Vgl}$. Fichtenaus Zusammenfassung seiner Ergebnisse: Askese und Laster 124 [106: Der Schluss des Texres ist in der überarbeiteten Version deutlich verändert]. Eine vergleichbare Interpretation bietet einer der profundesten Kenner der mittelalterlichen Überlieferung zu Tugenden und Lastern, Richard NewHAUSER in einem seiner aktuellen Beirräge: Newhauser, Vices as Anthropology (wie Anm. 12), v. a. 123.

33 Elias, Zivilisationsprozess (wie Anm. 11); die schärfste Kritik stammt von Hans Peter Duerr, Der Mythos vom Zivilisationsprozess, 5 Bde. (Frankfurt am Main 1988-2002); vgl. besonders RosenwEIN, Theories of Change (wie Anm. 3), mit umfassender weiterführender Literatur.

34 Für einen Überblick grundlegend DIEs., Worrying about Emotions in History. American Historical in die Psyche bzw. die Gefühlswelt der Menschen blicken, geschweige denn kollektive psychische Befindlichkeiten ausmachen können. Sehr wohl aber können wir Repräsentationen von Emotionen - Begriffe, Rhetorik, die Inszenierung von Gefühlen - analysieren, die uns in unterschiedlichen Formen der Überlieferung im Rahmen von kulturellen Modellen und Mustern begegnen, aus denen Menschen im Sinn von Repertoires schöpfen ${ }^{35}$ Sehr wohl können wir außerdem danach fragen, inwieweit sie gemeinschaftlich ausgeübt wurden, innerhalb von „emotional communities“, wie es Barbara Rosenwein vorschlägt. Beide Konzepte ermöglichen es, die gerade von Fichtenau immer wieder angesprochenen Ambivalenzen und Gleichzeitigkeiten unterschiedlicher Vorstellungen zu analysieren und sich so Schritt für Schritt einem komplexeren Bild der Vergangenheit anzunähern. Mein Interesse gilt den Fragen, welche Rolle Emotionen für die Entstehung und den Bestand von Gemeinschaften hatten sowie welche Rolle dabei der Askese als zeit- und milieuspezifische Ordnungstechnik der Affektkontrolle zukam.

Zu den Begriffen: „Emotion" ist eine moderne Kategorie, die keine direkte begriffliche Entsprechung in den Quellen hat, sondern der abstrahierenden „Übersetzung" in der wissenschaftlichen Kommunikation dient. Affekte (affectus) bzw. Leidenschaften (passiones) sind hingegen Quellenbegriffe, die bestimmte Aspekte emotionalen Verhaltens bezeichnen. Als Kategorien des zeitgenössischen Sprechens über Gefühle haben sie den Vorteil, dass sie uns helfen, uns der Vergangenheit in den ihr eigenen Termini anzunähern, und den Nachteil, dass sie Aspekte ausgeblendet lassen, die für die Zeitgenossen weniger maßgeblich waren ${ }^{36}$. Modelle bzw. exemplarische Vorbilder wiederum sind ebenso wie Gemeinschaften den mittelalterlichen Zeitgenossen geläufige und in ihrer täglichen Praxis verankerte Vorstellungen. Dass es sich bei exemplarischen Modellen und emotionalen Repertoires um kulturelle Konstruktionen handelt, ebenso wie „emotional communities" immer auch „imagined communities“ sind, tut ihren Effekten auf die und in der gelebten Praxis der Menschen keinen Abbruch. Das macht die reiche Überlieferung praktisch pastoraler Theologie gerade des Spätmittelalters mehr als deutlich.

Dies möchte ich an ausgewählten Beispielen der vierten Distinktion „Über die Versuchung" (de tentatione) des Dialogus miraculorum (DM) zu zeigen versuchen, deren Aufbau dem seit Gregor dem Großen klassischen Lasterkatalog folgt. Mit seiner um 1220 verfassten Sammlung von insgesamt 746 kurzen, exemplarischen Wundergeschichten in 12 Büchern (distinctiones), die in Form eines Dialogs zwischen einem erfahrenen Mönch und einem Novizen präsentiert werden, hat Caesarius von Heisterbach eine pastorale Anleitung für das „richtige" geistliche Leben verfasst, die primär im monastischen Raum verortet ist: Die meisten Geschichten betreffen Menschen, die sich in der einen oder anderen Weise für ein Leben im Kloster v. a. des Zisterzienserordens entschieden haben ${ }^{37}$.

Review 6 (2002) 821-845; Rüdiger SCHNELL, Historische Emotionsforschung. Eine mediävistische Standortbestimmung. FMSt 38 (2004) 173-276, und DERs., Emotionsdarstellungen im Mittelalter. Aspekte und Probleme der Referentialitär. ZfdPh 127 (2008) 79-102; Le sujet des émotions au Moyen Âge, hg. von Piroska bleme der Referentializär. ZfaPh 127 (2008) 79-102; Le sujet des émotions au Moyen Age, hg.
NAGY-Damien Boquet (Paris 2009); sowie die Beiträge in: History of Emotions (wie Anm. 3).

${ }_{35} \mathrm{Zu}$ Begriff und Konzept vgl. LutTER, Emotional Repertoires (wie Anm. 3) mit Bezug auf Gadi ALGAzI, Kulturkult und die Rekonstruktion von Handlungsrepertoires. L'Homme. Europäische Zeitschrift für feministische Geschichtswissenschafi 11/1 (2000) 105-119.

${ }^{36}$ Um möglichst quellennah ein breites Spektrum an Bedeutungen von Emotionen fassen zu können, empfiehlt sich daher ein jeweils genau ausgewiesener paralleler Gebrauch von Quellentermini und Forschungskategorien. Zur Problematik der Terminologie sehr ausführlich SCHNELl, Emotionsforschung, und DERS. Emotionsdarstellungen; sowie NAGY-BoQuET, Le sujet (alle wie Anm. 34)

37 Eine gute Forschungsübersicht bieter die Einleitung zur 2009 erschienenen zweisprachigen Ausgabe 
Gleichzeitig reflektieren die Wundergeschichten des Caesarius ein breites soziales Spektrum mittelalterlicher Gesellschaftsstrukturen zu Beginn des 13. Jahrhunderts. Zu diesem Zeitpunkt waren geistliche und weltliche Ordnungs- und Organisationsstrukturen grundlegenden Veränderungen unterworfen. Der einstige Reformorden der Zisterzienser hatte sich etabliert und Konkurrenz durch die neuen Predigerorden erhalten ${ }^{38}$. Diese richteten sich nicht nur an ein Publikum in den Klöstern, sondern predigten auch den Laien "in der Welr" ${ }^{39}$. Dementsprechend hatten die neuen Orden ihre Standorte besonders in den Städten und fanden dort große Resonanz. In dieser Konkurrenzsituation ebenso wie in der zunehmend besseren schriftlichen Organisation und Überlieferung sind Texte wie der Dialogus miraculorum verortet. Die sehr umfangreiche Verbreitung der Wundergeschichten in über hundert noch heute erhaltenen Handschriften legt ihre Relevanz und Attraktivität nahe ${ }^{40}$

Das Reizvolle an Caesarius' Darstellung als Untersuchungsgegenstand für die hier aufgeworfenen Fragen ist nicht zuletzt, dass er einerseits didaktisch systematisierend vorgeht und dementsprechend das zeitgenössische moraltheologische Verständnis sozusagen "für Anfänger" zusammenfasst, dass sein Text aber selbst im Sinn einer affekriven Didaxe funktioniert, weil seine exempla durch Lebensnähe, Nachvollziehbarkeit, Drastik wirken sollen - also verwundern und erschrecken, unterhalten und erbauen, und dadurch auch im Gedächtnis bleiben. Dabei ist nicht zuletzt die Popularität des Genres „Dialog“ seit der Antike als didaktisches Instrument zur Vermittlung exemplarischer Inhalte an ein $\mathrm{Pu}$ blikum beiderlei Geschlechts sowohl im geistlichen wie auch im weltlichen Bereich mit zu bedenken ${ }^{41}$. Caesarius redet also über Laster als Emotionen (und auch über Tugenden),

(lat./dt.) des DM sowie die Bibliographie in Bd. 5 der Ausgabe (wie Anm. 4). Grundlegend zum Genus exemplum ist Claude Bremond et al., L' „Exemplum" (Typologie des sources du moyen âge occidental 40, Turnhou 21996); Úbersichten zu mittelalterlichen miracula bieten: Miracle et Karăma. Hagiographies médiévales comparées, hg von Denise ArGLE (Turnhout 2000); Mirakel im Mittelalter Konzeptionen - Erscheinunguform Deurungen, hg von richte des frühen und hohen Mittelalters, hg. von Klaus Herbers (Ausgewählte Quellen zur Deutschen Geschichte des Mittelalters 43, Darmstadt 2005). Zum hier relevanten Kontext: Uta KLEINE, Gesta, Fama, Scripta. Rheinische Mirakel des Hochmittelalters zwischen Geschichtsdeutung, Erzählung und sozialer Praxis (Stuttgart 2007). Grundsätzlich Bynum, Christian Materiality (wie Anm. 9) Kap. IV.

38 Eine sehr gute Übersicht über den Stand der Forschung zur Entwicklung des Zisterzienserordens bieten die Beiträge in Franz FeITEN-Werner Rösener, Norm und Realitär. Kontinuitär und Wandel der Zisterzienser im Mittelalter (Berlin u. a. 2009); vgl. auch die umfangreiche Bibliographie zur Neuedition des Dialogu miraculorum. Für eine profunde vergleichende Diskussion vgl. Franz J. FeLren, Wozu treiben wir vergleichende Ordensgeschichte?, in: Mittelalterliche Orden und Klöster im Vergleich. Methodische Ansätze und Perspektiven, hg. von Gert Melville-Anne Müller (Vita regularis 34, Münster 2007) 1-51. Zur sozialen Kontextualisierung vgl. besonders die Arbeiten von Klaus SchreIner, Mönchsein (wie Anm. 5); DERS., Frömmigkei (wie Anm. 18), sowie DERs, Zisteriensisches Mönchtum und soziale Umwelt. Wirtschnflicher und sozialer Strukturwandel in hoch- und spärmirtelaltrerlichen Zisterzienserkonventen, in: Die Zisterzienser. Ordensleben zwischen Ideal und Wirklichkeit, hg. von Kaspar ELM (Köln 1982) 79-135.

${ }^{39}$ Aus der umfangreichen Literatur zum Anstieg pastoraler Literatur in Hoch- und Spätmittelalter vgl. hier nur spezifisch zum Gegenstand der Tugenden und Laster: Morton W. BLoomfield er al., Incipits of Lati Works on the Virtues and Vices, 1100-1500 A.D. (Cambridge, Mass. 1979), und Richard Newriauser-István Bejczy, A Supplement to Morton W. Bloomfield et al., Incipits of Latin Works on the Virtues and Vices, 1100-1500 A.D. (Turnhout 2008).

40 Vgl. die Einleitung zur Ausgabe von 2009 mit einem sehr ausführlichen wissenschaftlichen Apparat. $\mathrm{Zu}$ Quellen, Publikum und Rezeption des Dialogus miraculorum und verwandter Öberlieferung besonders die Arbeiten von Brian P. McGuire, Friendship and Faith: Cistercian Men, Women, and their Stories, 1100-1250 (Aldershor 2002); DERs., Friendship and Community. The Monastic Experience, 350-1250 ('Ithaca 2010).

41 Vgl. Mirko Breitenstein, „Ins Gespräch gebracht“: Der Dialog als Prinzip monastischer Unterwei- er erläutert Begriffe und bewertet Affekte, er erzählt und inszeniert emotional und spricht die Gefühlsebene seines Publikums an. Zudem ist Affekt ein konstitutives Element von Gemeinschaft. Das wird besonders seit den monastischen Reformbewegungen und v. a. bei den Zisterziensern betont und in den an der pastoralen Praxis orientierten Geschichten des Dialogus miraculorum deutlich ${ }^{42}$.

Konkret möchte ich nun anhand von Beispielen aus dem Dialogus miraculorum die oben akzentuierten Aspekte der Lektüre von „Askese und Laster" vertiefen. Der Schwerpunkt wird dabei auf einer Diskussion von superbia (vs. humilitas) und accidialacedia (vs. spiritalis iocunditas) liegen. In beiden Fällen geht es um Laster bzw. Tugenden, die einerseits einen spezifischen Sitz im monastischen Gemeinschaftsleben haben, anhand derer Caesarius aber andererseits auch die Abgrenzung zwischen geistlichem und weltlichem Stand sowie viele Fragen des richtigen Lebens in der Welt erörtert. Gleichzeitig lassen sich beide in Hinblick auf die oft ambivalente Bewertung von Freude und Fröhlichkeit, moderater Trauer und Verzweiflung und die ebenfalls je nach Zusammenhang unterschiedlich eingeschätzten Artikulationen des Lachens und Weinens diskutieren ${ }^{43}$

Die Frage nach dem Wandel der Hierarchie der Laster, der Einschätzung, was als Hauptübel bzw. -gefahr anzusehen ist, eröffnet - so eine der Grundthesen Fichtenaus - Einsichten in äußeren Lebensstil und innere Haltungen einer Epoche ${ }^{44}$ : Die Lehre von den acht, seit Gregor dem Großen sieben Hauptlastern lässt sich in seinem Sinn als generelle Richtschnur identifizieren, auch wenn sie seit dem Früh- und Hochmittelalter zunächst im Zusammenhang mit der asketischen Arbeit geistlicher Menschen an Körper und Geist auf dem Weg zur Wiederherstellung der göttlichen Ordnung und Vollkommenheit diskutiert wurde ${ }^{45}$. Dieses Verständnis finden wir auch im Dialogus miraculorum

sung, in: Understanding Monastic Practices of Oral Communication (Western Europe, Tenth-Thirteenth Centuries), hg. von Steven VANDERPuTten (Turnhout 2011) 205-229. Aus geschlechrergeschichtlicher Perspektive Sabina Flanagan, The Speculum virginum and Traditions of Medieval Dialogue, in: Listen, Daughter. The Speculum Virginum and the Formation of Religious Women in the Middle Ages, hg. von Constant J. Mews (New York 2001) 159-179, sowie die Beiträge von Karl Brunner, Eva Cescurti und Christina Lutrer, in: Funktionsräume, Wahrnehmungsräume, Gefühlsräume. Mitrelalterliche Lebensformen zwischen Kloster und Hof, hg. von DERS. (VIÖ 59, Wien 2011).

42 Bereits Jean Leclerce, Lamitié dans les lettres au moyen âge. Revue du moyen àge latin 1 (1945) 391-410; grundlegend Bynum, Cistercian Conception of Communiry (wie Anm. 20), zu Gemeinschaftsvorstellungen bei den Zisterziensern; exemplarisch BoQuET, L'ordre de l'affect (wie Anm. 19).

${ }_{43}$ Zum zulezzt genannten Aspekt vgl. jetzt Winfried WILHELMY, Das leise Lachen des Mittelalters - Lächeln, Lachen und Gelächter in den Schriften chrisclicher Gelehrter (300-1500), in: Seliges Lächeln, höllisches Gelächrer. Das Lachen in Kunst und Kultur des Mittelatters. Katalog zur Ausstellung im Bischöflichen Domund Diözesanmuseum, 27. 4.-16. 9. 2012, hg. von DEMs. (Regensburg 2012) 38-55; Bibliographie 241-251.

${ }^{44}$ Fichtenau, Askese und Laster 946. [85], mit Beispielen aus dem Alten und dem Neuen Testament. Diese Ambivalenz hinsichtlich der Rangfolge wird auch im 4. Buch des DM deutlich.

45 Fichtenau, Askese und Laster 89 [82f.]. Vgl. Cassian, Conlationes patrum, lib. 5, c. 10, ed. Michael Petschenig (CSEL 13, Wien 1886), bes. 129f. zur Verknüpfung (concatenatio) der Laster; sowie Gregor d. Große, Moralia in Iob (wie Anm. 25), lib. 31, c. 45, 88f., 1610 f. Zur Enrwicklung grundlegend Siegfried Wenzel, The Seven Deadly Sins: Some Problems of Research. Speculum 43/1 (1968) 1-22; Richard Newhauser, The Treatise on Vices and Virtues in Latin and the Vernacular (Typologie des sources du moyen âge occidental 68, Turnhour 1993), und Carla Casagrande-Silvana Vecchio, I sette vizi capitali. Storia dei peccati nel Medioevo (Torino ${ }^{32006), ~ s o w i e ~ d i e ~ B e i t r a ̈ g e ~ i n: ~ I n ~ t h e ~ G a r d e n ~ o f ~ E v i l . ~ T h e ~ V i c e s ~ a n d ~ C u l t u r e ~ i n ~ t h e ~ M i d d l e ~ A g e s, ~ h g . ~ v o n ~ R i c h a r d ~}$ Newhauser (Toronto 2005), und in: Laster im Mittelalter (wie Anm. 12). Zusammenfassend NewHAuSER, Vices as Anthropology (wie Anm. 12), bes. 112f. zur Vorstellung der concatenatio sowie $116 f$. explizit mit Bezug auf die Askese in geistlichen Gemeinschaften:, ....we can consider concatenation a way of endorsing the ideology of asceticism and also as a symbol of monastic culture itself." Einführung in die antiken Laster-Konzeptionen in Hinblick auf eine Geschichte der Emotionen vgl. Sorabj1, Emotion (wie Anm. 7); KnuUtrila, Emotions (wie Anm. 7). 
wieder, wenn Caesarius in den einführenden Erläuterungen zu seinem Buch über die Versuchung diese als grundsätzlich menschliche, aber spezifisch monastische Angelegenheit definiert. Ausgehend von Iob 7, 1 schreibe er über das Leben des Menschen, et militia est et tentatio; militia propter exercitium, tentatio propter laborem et periculum. Und weiter, anthropologisch: „... eine Versuchung sei das Leben des Menschen und nicht der Tiere, weil er humane und rationabiliter lebe, wie das Leben der Ordensleute beschaffen sei, die nach dem Geist lebten und nicht die Begierden des Fleisches erfüllten (Gal 5, 16). Die weltlich und fleischlich Gesinnten (saeculares vero et carnales), die gemäß dem Fleisch leben, werden nur uneigentlich Versuchte genannt, weil sie, sooft sie die Versuchungen spüren, entweder einwilligen oder zögerlich Widerstand leisten, ähnlich wie Pferd und Maultier, die keinen Verstand haben ${ }^{46}$. Wenn also das Leben der Ordensleute (religiosorum vita), die durch Wachen, Fasten, Beten, Gehorsam in guten und in schlechten Zeiten und durch Verzicht auf irdischen Besitz um Christi willen immer den Lastern und Begierden (vitiis et concupiscentiis) widerstehen, eine Versuchung ist, dann mußt Du einräumen, daß die Versuchung eine Wiedergutmachung für ihre Sünden ist" ${ }^{\text {"47 }}$.

Dieser Definition der Versuchung entspricht die Positionierung des vierten Buchs im DM nach jenen über die Bekehrung, die Reue und das Bekenntnis, sowie seine Binnengliederung entlang des gregorianischen Lasterkatalogs: In insgesamt 103 Kapiteln werden die sieben Laster Stolz (superbia), Zorn (ira), Neid (invidia), die nur schwer in einen einzelnen Begriff zu fassende acedia, Geiz (avaritia), Völlerei (gula) und Unkeuschheit/Geilheit (luxuria) jeweils definiert und in ihren Zusammenhängen sowie mit ihren „Töchtern“, d. h. aus ihnen abgeleiteten Sünden, anhand unterschiedlich zahlreicher Beispiele vorgestellt ${ }^{48}$. Dabei erläutert Caesarius immer wieder Aspekte zeitgenössischer Affekttheorie, die parallel mit dem Anwachsen theoretischer und praktischer Schriften zur Laster- und später auch Tugendlehre gerade zu seiner Zeit im Grunde zum ersten Mal seir der Patristik wieder einer grundlegenden Systematisierung unterzogen wurden ${ }^{49}$.

Seit Gregor dem Großen galt Hochmut als Wurzel aller Laster. Superbia ist die Sünde Satans und damit die erste und grundlegendste Sünde überhaupt; sein Laster besteht im Nicht-Dienen-Wollen, in der Nicht-Unterwerfung unter Gott. Konsequenz ist die Orientierung auf das Selbst und der „Wunsch nach einzigartigem Herausgehobensein über andere "50. Das ist ein Laster, das sich nicht nur bei Weltlichen, sondern auch bei Geistlichen findet, so Caesarius $^{51}$. Die ersten Kapitel machen die Parallelität geistlicher und weltlicher Persönlich-

${ }_{46}$ DM lib. 4, c. 1 (wie Anm. 4) 668-669. Vgl. Iob 7, 1: militia est vita hominis super terram et sicut dies mercennarii dies eius.

47 Ebd. 670/671.

48 DM lib. 4, c. 2, ebd. 626/627; vgl. oben Anm. 45.

49 Besonders in der Summa theologiae des Thomas von Aquin; vgl. Miner, Thomas Aquinas (wie Anm. 31); für eine vergleichende Einschärzung Rosenwein, Theories of Change (wie Anm. 3). Zum Anstieg der Überlieferung zu Lastern und Tugenden vgl. Bloomfield, Incipits, und Newhauser-Bejczy, Supplement (wie Anm. 39)

so Fichtenau, Askese und Laster 97 [87]. Gregor der Große, Moralia in lob, lib. 31, c.1, 1 (wie Anm. 25) 1549 und lib. 31 , c. 45, 87, ebd. 1610. Johannes Cassian, De institutis coenobiorum et de octo principalium uitiorum remediis libri XII, ed. Micheal PETSCHINIG, editio altera supplementis aucta cur. Gotffried KreUz (CCSL 17. Wien 2004) lib. 12, c. 6, 205 sowie 209f.: Quod superbiae uitium, cum sit in ordine conluctationis extremum, tempore tamen et origine primum sit, und Augustinus, De civitare Dei, lib. 14, c. 13, ed. Bernard DomBrTKalB (CCSL 47 und 48, Turnhour 1955) 436, setzen superbio zeiclich, aber nichr kausal an die Spirze.

51 DM lib. 4, c. 3 (wie Anm. 4) 676/677: De superbia et filiabus eius: ... Superbia, quae primum locum tenet inter vitia, est singularis excellentiae super alios quidam appetitus.... Quantum per vitium superbiae caro, mundus et diabolus non solum saeculares, sed et personas claustrales tentent, sequentia declarabunt. keits- und Standesideale, die Abgrenzungsversuche und damit gleichzeitig die Schnittstellen zwischen Kloster und Welt deutlich. Wie sehr das Christentum bestehende weltliche Standesideale integrierte, wenn auch modifizierte, betont auch Fichtenau am Beispiel der bereits knapp 200 Jahre vor dem Dialogus verfassten Lebensbeschreibung Erzbischof Adalberts ( $\dagger$ 1072) durch Adam von Bremen ${ }^{52}$ : Die Konvergenz von geistlichen und weltlichen Persönlichkeitsidealen, letztere repräsentiert durch Herkunft, Größe, Schönheit, Glück und Reichtum, führt ungeachtet aller Tugenden Adalberts zu einem vom Geist des Stolzes regierten Verhalten. Die grundsätzliche Frage nach dem richtigen Verhältnis von Adel der Herkunft und Adel der Tugend und nach dem Umgang mit den sie begleitenden äußeren Formen von nobilitas ist ein zentrales Thema zahlreicher hoch- und spätmittelalterlicher spiritueller und didakrischer Traktate, so etwa des breit rezipierten Speculum virginum, eines an geistliche Frauen gerichteten pastoralen Dialogs aus der Mitte des 12. Jahrhunderts ${ }^{53}$.

Quanto estis ceteris nobilior, tanto esse debetis humilior, muss sich ganz ähnlich in einem von Caesarius gegebenen Exempel ein Mönch hoher Herkunft wegen seines allzu selbstbewussten standesgemäßen Auftretens in modischen Schuhen vom französischen König also einem Weltlichen, wenn auch höchsten Ranges - tadeln lassen, zu dem er von seiner Gemeinschaft mit der Bitte um Hilfe gegen die Übergriffe eines Adeligen auf das Kloster geschickt worden war. Diese Geschichte bringt Caesarius in gleich zwei auf einander folgenden Versionen, einmal mit einem Benediktiner, einmal mit einem Zisterzienser in der Rolle des durch den König des Hochmuts Überführten und Beschämten ${ }^{54}$.

Noch häufiger äußert sich im monastischen Raum und in der asketischen Praxis superbia allerdings als Stolz auf die eigene Leistung, eine Versuchung, der gerade besonders tugendhafte geistliche Menschen ausgesetzt sind. Denn mit dem Voranschreiten auf dem spirituellen Weg wächst auch die Gefährdung. Gerade die täglichen monastischen Übungen und besonders die opera sacra et honesta - Beten, Singen, das Beweinen der Sünden - können Gegenstand der hochmütigen Haltung und eines eitlen Handelns werden. Eigene Fähigkeiten, etwa „die Süßigkeit und der Wohlklang" der Stimme beim Psalmodieren, das Wissen und die Beredsamkeit der Prediger werden zur Versuchung für geistliche Menschen. Caesarius zitiert Augustinus, der bekennt, schwer gesündigt zu haben, wenn ihn der Gesang mehr als sein Inhalt erfreut habe ${ }^{55}$. Ja selbst die Gnade der Tränen ist ein potentieller Angriffspunkt für Prüfungen durch Gott, um Überheblichkeit aufgrund der Regelmäßigkeit dieses göttlichen Geschenks zu vermeiden, ebenso wie für Versuchungen durch Dämonen und den Teufel, dem geistliche Übungen ein Gräuel sind ${ }^{56}$.

52 Fichtenau, Askese und Laster 111-115 [97-100], mit einer Reihe von einschlägigen Zitaten: Adam von Bremen, Hamburgische Kirchengeschichte, lib. III (wie Anm. 9) 143f., 145f., 150, 170, 180; sowie 115: zur Trias inanis gloria als Tochter der superbia und invidia mit Hinweis auf Augustinus, De civitate Dei (wie Anm. 50), und Gregor den Großen, Moralia in Iob (wie Anm. 25).

53 Speculum virginum/Jungfrauenspiegel (lat./dt.), übers. und eingel. von Jutta SEYFARTH, 4 Bde. (Fontes Christiani 30/1-4, Freiburg im Breisgau u. a. 2001), besonders das vierte Buch, in dem die Tugenden und Laster anhand der Baum-Metaphorik gegenübergestellt werden, und das neunte Buch zum Fortschritt auf der Tugendleiter, wo die Idee der "wahren Nobilität" mit Bezug auf Kor 1, 26-29 diskutiert wird: lib. 9, ebd. 764-767; ausführlich die Beiträge in Mews, Listen Daughrer (wie Anm. 41). Ähnlich auch das St. Trudperter Hohelied, besonders lib. 12, c. 21 (wie Anm. 20) 42f., mit ausführlichem Kommentar von Friedrich ОнцY und weiteren Belegen in zeitgenössischen geistlichen und weltlichen Texten, 574-578.

54 DM lib. 4, c. 12 und 13 (wie Anm. 4) 702-705, das Zitat auf 702/703.

55 DM lib. 4, c. 8, ebd. 692/693, nach Augustinus, Confessiones, lib. 10, c. 33, ed. Luc Verheijen (CCSL 27, Turnhout 1981) 182; die übrigen Zitate aus DM lib. 4, c. 7 (wie Anm. 4) 690f.

56 Zur Gnade der Tränen siehe z. B. DM lib. 2, c. 22 (wie Anm. 4) 444f.; dazu Piroska NAGY, Le don des 
Stolz und Hochmut treten also in den unterschiedlichsten Formen und Ausprägungen auf, und gerade auch dort, wo man es nicht erwarten würde. Diesem Befund entspricht auch die Verteilung der Geschichten des vierten Buchs: Auf den ersten Blick ist der Anteil der exempla im Abschnitt über den Hochmut im Unterschied zu anderen Lastern vergleichsweise kurz (13 Kapitel; 12 exempla), vor allem im Vergleich mit jenen zur acedia, die in 30 Kapiteln, d. h. in knapp einem Drittel des gesamten Buchs behandelt wird. Bei genauerer Untersuchung wird deutlich, dass die Diskussion der superbia als Wurzel allen Übels immer wieder integraler Bestandteil der Diskussion der übrigen Laster ist. Das gilt gerade auch für die körperlich konnotierten Laster wie luxuria vs. Keuschheit, wenn etwa aus der asketischen Leistung der Enthaltsamkeit Hochmut erwächst und sich die Tugend auf diese Weise in ein Laster verkehrt. Solche Leute, erklärt Caesarius, fürchtet der Teufel nicht, und Gott findet an ihrer Leistung keinen Gefallen ${ }^{57}$. Wenn die asketische Leistung zur Selbstverständlichkeit oder zum Selbstzweck wird oder aber der Selbsterhebung dient, münden übertriebene asketische Leistungen entweder in die Sünde der superbia oder in jene der acedia ${ }^{58}$.

Bereits bei Johannes Cassian (360-435), dessen Adaption des von Evagrius Ponticus (345-399) entwickelten Achtlasterschemas im lateinischen Westen gemeinsam mit der Lehre Gregors des Großen am einflussreichsten wurde, sind Grund und äußeres Zeichen für hochmütiges Verhalten in der Absonderung des Einzelnen von der monastischen Gemeinschaft zu sehen ${ }^{59}$. Dementsprechend ist Demut (bumilitas) die zentrale monastische Tugend. Devotionsformeln und Bescheidenheitstopik finden sich bei Geistlichen aller Stände im Sinn der geforderten Unterwerfung des Selbst unter Gott bzw. unter die göttliche Weltordnung, und darüber hinaus auch bei Weltlichen - gerade auch jenen hohen Ranges. Doch selbst sie kann sich ins Gegenteil verkehren: Gregor der Große wendet sich gegen konventionelles Demutsverhalten nach außen, dem die innere Haltung nicht entspricht. Caesarius kritisiert in diesem Sinn jene, die mit ihren geistlichen Leistungen nur das Lob und den Lohn der Menschen erlangen wollen, als besonders dumm, denn mit Mt 6, 5 erhalten sie dann auch nur diese ${ }^{60}$. Stolz und Demut sind zwei Seiten einer Medaille. In diesem Punkt kann man wohl von langfristig stabilen und standesübergreifenden diskursiven und emotionalen Repertoires im christlichen Weltbild sprechen, die für Menschen unterschiedlichen Standes und vielfältiger Zugehörigkeiten vorbildlich und wirkmächtig waren ${ }^{61}$.

larmes au Moyen Âge (Paris 2000); zum Verlust dieser Gnade als Prüfung vgl. DM lib. 4, c. 30 (wie Anm. 4) 746/747; zur Missgunst des Teufels in diesem Zusammenhang DM lib. 4, c. 35, ebd. 760/761. Zur Bedeutun des Beweinens der eigenen Sünden im Kloster vgl. die Ermahnung eines zu sehr um das wirtschaftliche Wohlergehen seines Klosters bekümmerten Konversen: Mane ergo in claustro tuo, frequenta oratorium tuum, ut die noctuque possis peccata tua deplangere: DM lib. 4, c. 62, ebd. 828/829.

DM lib. 4, c. 5 (wie Anm. 4) 682/683: Nec Deo placet, nec diabolus timet sine humilitate virginitatem, cum tamen Deo placeat, et diabolus timeat sine virginitate humilitatem. Zur Verkehrung von Tugenden in Laster bzw. zur "Verkleidung" von Lastern als Tugenden vgl. Richard Newrhauser, On Ambiguity in Moral Theology. When the Vices Masquerade as Virtues, in: DERs., Essays on the Moral Tradition in the Western Middle Ages (Aldershor 2007).

58 Dazu ausführlich unten S. 106-108.

59 Cassian, De institutis coenobiorum, lib. 12, c. 30 (wie Anm. 50) 228f. Vgl. Conrad LeYser, Authority and Asceticism from Augustine to Gregory the Great (Oxford 2000).

60 Sancti Gregorii Magni Vita, a Johanne diacono scripta libris quatuor, lib. 3, c. 51, PL 75 161: DM lib. 4, c. 7 (wie Anm. 4) 690/691; zur Unterwerfung des menschlichen Willens unter jenen Gotres vgl. erwa Bernhard, Sermones de diversis 26 (Quomodo voluntas nostra divinae tripliciter subici debeat voluntati) n. 2 (Bernhard von Clairvaux, Sämtliche Werke lateinisch/deutsch, Bd. 9 [Innsbruck 1998] 408-415, hier 408/411): ... Porro totius humilitatis summa in eo videtur consistere, si voluntas nostra divinae, ut dignum est, subiecta sit voluntati,..

${ }_{61}$ Fichtenau, Askese und Laster 113f. [99], bringt mehrere Beispiele aus der höfischen Literatur z
In diesem Verständnis einer Entsprechung von „innerer Haltung“ und „äußerem Verhalten" wird auch die ambivalente Haltung mittelalterlicher Theoretiker und pastoraler Praktiker den Emotionen der Freude und Trauer und ihren Artikulationen, dem Lachen und Weinen, gegenüber deutlich. Superbia bringt die Dinge aus dem Lot und erzeugt Maßlosigkeit. Konsequenzen sind übergroße Fröhlichkeit oder Traurigkeit, d. h. als maßlos bewertete Emotionen: Der Mensch befindet sich eben erst auf dem Weg zur inneren Ordnung und himmlischen Freude und ist noch nicht dort. Törichte Fröhlichkeit gilt Bernhard von Clairvaux als Eigenschaft der Hochmütigen, die sich dem Schlechten und Traurigen in ihrer Seele nicht stellen wollen ${ }^{62}$. Caesarius von Heisterbach nennt in seinen einführenden Erläuterungen zur Völlerei als deren „Töchter“ unter anderem Narretei, unpassende Fröhlichkeit und Geschwätzigkeit. Ausgelassenheit und lautes Lachen sind Eigenschaften der Dämonen, und so werden auch im Dialogus miraculorum zahlreiche Mönche nach geglückter Versuchung durch Teufel und Dämonen von diesen verhöhnt und vor der Gemeinschaft zum Gespött gemacht ${ }^{63}$.

Petrus Venerabilis geht noch weiter, wenn er die Wahl der Farbe Weiß für den zisterziensischen Habit gegenüber dem benediktinischen Schwarz als dem Tal der Tränen und der Aufgabe der Buße nicht angemessen kritisiert. Angebracht ist maßvolle Trauer, die Gabe der Tränen ist ein Geschenk, während übermäßige Trauer bis zu völliger Mutlosigkeit und Verzweiflung führen $\mathrm{kann}^{64}$. Dieser Versuchung sind viri religiosi in besonderer Weise ausgesetzt, was sich im DM in der erwähnten hohen Zahl an einschlägigen exempla äußert. Der Integration von tristitia und acedia durch Gregor den Großen entspricht die thematische Gliederung dieses Abschnitts bei Caesarius. Er erklärt die Zusammenhänge seinem fiktiven Schüler so: Accidia est ex confusione mentis nata tristitia, sive taedium, et amaritudo animi immoderata, qua iocunditas spiritalis extinguitur, et quodam desperationis praecipitio mens in semetipsa subvertitur ${ }^{65}$.

dieser Parallelität von weltlicher Ehre und Seelenheil, u. a. aus dem Kreuzlied Harrmanns von Aue: Wan swem daz ist beschert, daz er da wol gevert, daz giltet beidiu teil, der welte lop, der selle heil: Des Minnesangs Frühling, bearb. von Hugo Moser-Helmut Tervooren, Bd. 1: Texte (Stuttgart 1988) XXII. Hartmann von Aue, V Dem kriuze zimet wol reiner muot 2, Z. 9-12, 412-414.

62 Fichtenau, Askese und Laster 37-41 [44-47]; 38 [45] mit dem Zitat von Bernhard von Clairvaux, Liber de gradibus humilitatis et superbiac, c. XII (Bernhard von Clairvaux, Sämtliche Werke lateinisch/deutsch, Bd. 2 [Innsbruck 1992] 29-135, hier 104-107): Tertius gradus (superbiae]: De inepta laetitia: Proprium est superborum, laeta semper appetere et tristitia devitare, iuxta illud: Cor stultorum, ubi laetitia (Eccle 7, 5).

${ }_{63}$ Explizit etwa in DM lib. 4, c. 33: quantum daemones illic dormitantes irrideant, oder DM lib. 4, c. 34: Vide quanta subsannatio ..., beide (wie Anm. 4) 758/759. Die 56 Kapitel der fünften Distinktion des DM sind zur Gänze den Dämonen gewidmet (Distinctio Quinta: De daemonibus, DM [wie Anm. 4] 948-1133). Eindrucksvolle Beispiele lachender Dämonen bringt auch Otloh von St. Emmeram, Liber visionum, ed. von Paul Gerhard Schmidt (MGH Quellen zur Geistesgeschichte des Mitrelalters 13, Weimar 1989), Visio 4, 54-60, hier 57: „Numquid tu nobiscum gaudere et ioculari non vis? Quia ergo elegisti tristiciam, satis profecto experieris illam". Vgl. Thierry Lesieur, Othlon de Saint-Emmeran. La vie comme épreuve de la négativité, in: Moines er démons. Autobiographie et individualité au Moyen Âge (VII`-XIII siècle), hg. von Dominique BarthélemYRolf Grosse (Hautes Érudes Médievales et Modernes 106, Genève 2014) 101-118.

${ }^{64}$ The Letters of Peter the Venerable, edited, with an introduction and notes, by Giles Constable, 2 Bde. (Cambridge, MA 1967) 1 Nr. 28 an Bernhard von Clairvaux, 52-101, hier 57f.: Cumque in ualle lacrymarum positos (Psal 83, 7) quibus praecipitur ut semper luctui nunquam laetitiae intendant deceant uestimenta luctum et paenitentiam designantia, wos econtra in miseriis felicitatem in merare gaudium in luctu lactitiam uestium candore monstratis. Vgl. Fichtenau, Askese und Laster 40f. [46f.].

65 DM lib. 4, c. 27 (wie Anm. 4) 738/739, dazu im Apparat, Anm. 522, eine ausführliche Erläuterung zum Bedeutungsspektrum des Begriffs. Unterscheidung von acedia und tristitia bei Cassian, Conlationes patrum (wie Anm. 45) lib. 5, c. 2, 121; vgl. auch ders., De institutis coenobiorum, lib. 10, c. 1 (wie Anm. 50) 173f. 
Zunächst geht es um scheinbar harmlose Formen von Unlust im Alltag, um die Betäubung der Seele, wie es bereits Cassian ausführt, die zur Trägheit, Abneigung, ja Ekel gegenüber den geistlichen Übungen führt, dort etwa konkret um die Trägheit der Mönche zur heißen Mittagszeit ${ }^{6 \sigma}$. Sehr ähnlich sind auch die ersten Geschichten des Caesarius in diesem Abschnitt am monastischen Tagesablauf orientiert. Immer wieder geht es darum, dass die Mönche beim Gebet einschlafen oder gar nicht erst zum gemeinsamen Beten aufstehen. Häufig wird diese Versuchung durch Teufel oder Dämonen in Form von deren aktiven physischen Eingreifen geschildert. Der Teufel hindert einen Kölner Scholasticus in dessen Probejahr bei den Zisterziensern daran, seinen Mantel anzuziehen, um zum Chorgebet zu gehen. Einem Novizen drückt er jeweils vor dem Stundengebet so heftig auf die Schultern, dass er sich hinsetzen und ausruhen muss. Ein Mönch wird durch eingebildete Krankheiten daran gehindert, zur Matutin aufzustehen. Andere werden während des Chorgebets durch Schläfrigkeit versucht und, sobald sie eingeschlafen sind, auf verschiedene Weise verspottet ${ }^{67}$.

Die Ambivalenz menschlicher Schwäche wird in einer der längsten Geschichten des gesamten Buchs über den Mönch Christian aus dem St. Peterstal deutlich ${ }^{68}$. Christian war ein noch junger Mönch, der sich durch ein den Heiligen gleiches Leben auszeichnete. Dabei war er körperlich so schwach (corpore tam debilis), dass er des Lebens überdrüssig wurde (ut eum vivere taederet). Eines Nachts schlief auch er - ausgestreckt liegend, weil er seinen Kopf schonen wollte - während des Gebets vor dem Altar ein. Im Unterschied aber zu anderen Mönchen, die für ein solches Vergehen deutlich empfindlicher bestraft werden, wird Christian sanft von der Jungfrau Maria geweckt und freundlich ermahnt. Hier, so bemerkt der Novize im Dialog, ist tatsächlich körperliche Schwäche der Grund für das Fehlverhalten des herausragenden Asketen, aber - so antwortet der Lehrer - „wegen der Sünde des ersten Menschen ist jede Versuchung auch eine Schwäche". In der christlichen Lehre von der Erbsünde kommt das Erlebnis der Gemeinsamkeit diesem Zustand der Unordnung und Gefahr gegenüber zum Ausdruck. „Wir wollen uns also davor hüten“, so Caesarius weirer, „daß nicht das, was der Natur entspricht, zum Laster wird. Denn nicht nur aus dem Natürlichen entstehen durch Mißbrauch Laster, sondern auch aus Tugenden können Laster entstehen. Zum Beispiel: Wenn die Gerechtigkeit das rechte Maß überschreitet, wird sie zur Grausamkeit; allzu große Frömmigkeit führt zur Aufösung; übertriebener Eifer erweist sich als Wut; allzu große Milde nennt man Trägheit und Verdrossenheit" 69 .

Daher lässt sich, so auch Fichtenau explizit, die Gegenüberstellung von Fleisch (caro) und Geist (spiritus) im mittelalterlichen Verständnis nicht vereinfachend als Leibfeind-

Integration bei Gregor dem Großen, Moralia in lob, lib, 31, c. 45 (wie Anm. 25); dazu Siegfried Wenzel, The Sin of Sloth: Acedia in Medieval Thought and Literature (Chapel Hill 1967); Christoph Jozst, Die Bedeutung von Akedia und Apatheia bei Evagrios Pontikos. Studia Monastica 35 (1993) 7-53; Christoph FlüELER, Me-

lancholie und Acedia im Spätmitrelalter. Freiburger Zeitschriff für Philosophie und Theologie 34 (1987) 379-398.

Vgl. Fichtenau, Askese und Laster 92 [84].

66 Cassian, De institutis coenobiorum, lib. 10, c. 1 (wie Anm. 50) 174.

67 DM lib. 4, c. 49 (wie Anm. 4) 790-795: Scholasticus, hier 790/791; DM lib. 4, c. 52, ebd. 788-801, hier 800/801: Novize; DM lib. 4, c. 32-36, ebd. 756-763: schlafende Mönche.

68 DM lib. 4, c. 30 (wie Anm. 4) 742-753

69 Ebd. 744/745: Caveamus ergo, ne hoc quod est naturae, vertatur in vitium; quia non solum ex naturalibus per usum malum gignuntur vitia, sed etiam ex virtutibus. Verbi gratia: Justitia dum modum excedit, vertirur in crudelitatem; nimia pietas in dissolutionem; indiscretum zeli studium iudicatur iracundia; nimia mansuetudo segnitia dicitur et accidia. lichkeit interpretieren: caro ist nicht im Sinn von Körperlichkeit, spiritus nicht als Geist [an sich] zu verstehen, sondern jeweils als Haltung: caro als Hinwendung zur Welt, spiritus als spirituelle Haltung; sinnliche Bedürfnisse und Leidenschaften sollen durch die geistliche Haltung und ihre Übung kontrolliert werden ${ }^{70}$.

Dass sich die Umsetzung solcher Vorgaben in der täglichen Praxis weniger leicht darstellt als in der Theorie, kündigt Caesarius bereits im einführenden Kapitel zum vierten Buch mit den Worten an, er wolle mit den folgenden Beispielen darlegen, „wieviel Mühe die Versuchung enthält, wieviel Furcht, wieviel Aufwand und Lohn"71. Prüfung und Versuchung, Qualen, Angst und Schrecken dominieren dementsprechend die Themen und Motive, das Vokabular und die Inszenierung seiner Beispiele. Denn es ist auch nicht jeder bereits so weit auf dem geistlichen Weg fortgeschritten wie der erwähnte Christian. In einem anderen "ganz schrecklichen" (rem valde terribilem) Beispiel wird etwa ein beim Psalmodieren häufig schlafender Mönch vom Gekreuzigten selbst geweckt und mit einem Kinnhaken von solcher Gewalt niedergestreckt, dass er innerhalb von drei Tagen stirbt ${ }^{72}$ Die Begründung, die Caesarius für diese drastische Strafe gibt, unterstreicht explizit die Bedeutung eines gerade auch emotionalen Einsatzes, der von den geistlichen Menschen verlangt wird: „Ein gleichgültiger Mönch verursacht Gott und den heiligen Engeln Übelkeit. Daher lässt Johannes einen Gleichgültigen stellvertretend für alle durch Christus sagen, Wenn Du doch warm oder kalt wärest! Aber weil Du lau bist, werde ich Dich aus meinem Mund ausspeien' (Offb 3, 15f.)."

Am anderen Ende der emotionalen Skala stehen jene Formen von maßloser und daher sündhafter Traurigkeit, die zur völligen Verzweiflung bis hin zum Selbstmord führen können. Caesarius gibt insgesamt sechs solcher exempla, vier davon betreffen geistliche Menschen, von denen einer gerettet wird, zwei weltliche Personen ${ }^{73}$. Im Fall eines jungen Mannes, der seine Kleider verspielt und sich erhängt, findet Caesarius vergleichsweise leicht eine Erklärung in der Bergpredigt, wo jene selig gepriesen werden, die über ihre Sünden trauern und Buße tun (Mt 5, 4): Des Jünglings Kummer hingegen sei nicht Gott gemäß gewesen und deshalb eine Sünde ${ }^{74}$. Keinen Kommentar gibt es zum Tod einer Nonne, die von einem schlechten Konversen (maligno converso) verführt in einen Brunnen springt, und zum freiwilligen Tod eines Mädchens, das von einem nicht näher genannten Mann (quodam viro) geschwängert und verlassen wurde ${ }^{75}$. Weitere Fälle betreffen besonders tugendhafte geistliche Menschen beiderlei Geschlechts, die trotz vorgerückten

70 Fichtenau, Askese und Laster 29 [39]; ähnlich 90 [82], anhand der Diskussion der „körperlichen" Laster (vitia carnalia) Völlerei und Unzucht, die in der Lasterhierarchie zunächst an erster Stelle standen, z B. bei Cassian, Conlationes patrum, lib. 5, c. 3 (wie Anm. 45) 121f., mit Bezug auf Evagrius Ponticus; dazu Newrhauser, Vices as Anthropology (wie Anm. 12) 115, während sie bei Gregor, Moralia in Iob, lib. 31, c. 45, 88-90 (wie Anm. 25) 1611-1613, den fünf vitia spiritalia nachgereiht sind. Nicht die sinnlichen Bedürfnisse an sich sind die Sünde, sondern ihnen nachzugeben ( $d$. h. von ihnen "beherrscht" zu werden anstatt sie zu beherrschen). Vgl. auch hier die Parallelen zu höfischen Tugend- und Lastervorstellungen, z. B. Horst WenzeL, Se regere. Affekt und Repräsentation in der höfischen Literatur, in: Emotions and Material Culture, hg. von Gerhard JARITZ (Wien 2003) 101-122. Grundlegend Bynum, Soul and Body (wie Anm. 9).

DM lib. 4, c. 1 (wie Anm. 4) 672/673: Quantus sit in tentatione labor, quantus timor, quantum dispendium, quantumve meritum, sequentia declarabunt exempla.

DM lib. 4, c. 38, ebd. 764/765: De monacho in choro frequenter dormitante, quem crucifixus in maxill percussit et extinxit.

73 DM lib. 4, c. 40-45, ebd. $772-785$.

74 DM lib. 4, c. 44, ebd. 780/781: Vides nunc, quam periculosa sit tristitia, quae non est secundum Deum?

75 DM lib. 4, c. 42, ebd. 778/789; DM lib. 4, c. 43, ebd. 778-781. 
Alters und vorbildlicher Lebensführung plötzlich so sehr von Zweifeln gequält werden, dass sie sich schließlich für verdammt halten und den Kampf aufgeben, wie es über einen verzweifelten Konversen heißt, der seine Gebete nicht mehr sprechen konnte und deshalb Angst vor der Hölle bekam. Er sprang nach den Worten: „Ich vermag nicht länger gegen Gott zu kämpfen " in den Fischteich des Klosters ${ }^{76}$. Erklärungen, warum Gott so etwas zulässt (Deus talia permittit), fallen hier offensichtlich auch dem geistlichen Lehrer schwer. Im Gespräch über eine Nonne, die sich in die Mosel stürzte, legt Caesarius dem Novizen die Vermutung in den Mund, „damit keiner, wie vollkommen er auch ist, sich auf seine Tugenden und Werke etwas einbildet, sondern sie ganz Gott zuschreibt, von dem das Gute zu wollen, zu können, zu tun und zu vollenden kommi"77, was der Lehrer bestätigt. Im letzten Fall des Konversen, den Caesarius gut kannte, folgt sie erst einige Kapitel später mit der Vermutung eines ungenannten gemeinsamen Bekannten, der Tote hätte niemals eine vollkommene Beichte abgelegt ${ }^{78}$

Leichter verständlich dürften auch den Zeitgenossen jene Beispiele gewesen sein, in denen geistliche Menschen aufgrund von übertriebener Askese dem Laster der acedia verfielen $^{79}$ : So erzählt Caesarius von einem Mönch namens Baldwin, dem die gemeinsamen asketischen Übungen nicht genügten, sodass er sie durch viele weitere "private" (privata) ergänzte, die ihm wichtiger waren. „Schließlich trocknete von allzu viel Wachen und Beten sein Gehirn aus und er wurde so schwachsinnig, dass er eines Nachts, noch bevor sich der Konvent zur Matutin erhob, die Kirche betrat, die forma der Novizen bestieg und mit dem Glockenseil um den Hals hinabsprang." Da die Glocke dabei zu läuten begann, liefen alle herbei, und er wurde gerettet, gewann aber seine geistigen Fähigkeiten nie wieder. Die Absonderung von der Gemeinschaft, wie sie bereits bei Cassian problematisiert wird, hat hier also dramatische Konsequenzen.

Für das unmittelbare Erleben ist Gemeinschaft aber nicht nur der notwendige disziplinierende Rahmen gegen superbia und acedia, sondern ebenso Ort der Tröstung angesichts des Ausmaßes an Schrecken, Qualen und Gefahren, wie Caesarius explizit unterstreicht ${ }^{80}$. Die affektiven Aspekte der Gemeinschaft werden in der Terminologie in differenzierter Weise deutlich. Die Klosterfamilie ist gleichzeitig familia im ökonomischen Sinn, wie sie emotional definierte Bindungen herstellt und aufrecht erhält: Nicht nur wird der Abt als Vater, sondern auch der Prior als Mutter imaginiert, die dafür verantwortlich sind, den Konvent, der den Leib Christi darstellt, „zu tragen, zusammenzuhalten und zu stützen: Zu tragen durch das Gebet, zusammenzuhalten durch die Disziplin und zu stützen durch das tröstende Wort". Zum Wohl der Gemeinschaft müssen beide ihre Aufgaben erfüllen, um den Leib Christi im Gleichgewicht zu halten ${ }^{81}$.

${ }_{76}$ Besonders DM lib. 4, c. 40 und 41, ebd. 772-778, hier 776/777: Non possum diutius contra Deum pugnare.

DM lib. 4, c. 40, ebd. 772-775, hier 774/775: ... forte ideo Deus talia permitrit, ne aliquis, quantumliber sit perfectus, de suis virtutibus vel virtutum operibus praesumat, sed Deo totum, a quo est bonum velle, posse, facere et perficere, attribuat.

78 DM lib. 4, c. 44, ebd. 780/781: De supradicto converso quidam vir sapiens, qui illum bene novit, me audiente sic ait: "Non credo quod unquam perfecte fecerit confessionem suam."

79 Die folgenden Zitate aus DM lib. 4, c. 45, ebd. 782/783, mit dem Fazit: Sic quandoque de indiscreto fervore nascitur vitium accidiac.

${ }_{80}$ Z. B. DM lib. 4, c. 47 , ebd. 7861787

81 DM lib. 4, c. 18, ebd. 718-721: Ad Abbatem enim et Priorem specialiter spectat conventum, qui Christi corpus est, portare, tenere et sustentare. Portare per orationem, tenere per disciplinam, sustentare per consolationem Abbas loco patris, Prior vice matris. Cum Prior cum Abbate suo minus bene concordat, non aequa lance cum illo
Selbst oder gerade ein bereits als „heilig" bezeichneter Mönch wie der oben erwähnte Christian leidet unter seinem durch physische Schwäche begründeten und damit legitimen Ausschluss vom gemeinschaftlichen Gebet. „Wenn ich nämlich außerhalb des Chores stehe und die anderen psallieren höre, tut es mir im Herzen weh, dass ich nicht hinzutreten darf, weil ich an die Tröstungen denke, mit denen Gott unter den anderen meine Seele erfreut." ${ }^{82}$

Die Trennung von der Gemeinschaft verunmöglicht ihm diese Tröstungen, und auf Nachfrage des Abtes erläutert er, dass diese in der Schau der Engel und Jesus Christus selbst bestünden ${ }^{83}$. Selbst in diesem Fall weiten Fortschritts auf dem geistlichen Weg werden die individuellen spirituell-emotionalen Bestrebungen - Christian wird als Braut Christi der Hoheliedmetaphorik dargestellt - nicht losgelöst von der Gemeinschaft, sondern in sie integriert gedach ${ }^{84}$. Und schließlich ist es das gemeinsame Gebet der Gemeinschaft, das individuelle Rettungschancen erhöht, wie in der dramatischen Geschichte einer Rekluse, die ihren Glauben zu verlieren droht und schließlich durch die besonderen und intensiven Gebete der Mitglieder jenes Zisterzienserklosters, dessen Abt die Aufsicht über sie anvertraut war, von ihren Zweifeln erlöst wird ${ }^{85}$.

Verbindungen zwischen den Tröstungen der Gemeinschaft und den sozialen Aspekten des Zusammenlebens stellen auch jene exempla der vierten Distinktion her, deren erbaulicher, immer wieder auch als unterhaltsam angekündigter Inhalt der Motivation des Publikums dienen soll. Ist allzu große Fröhlichkeit zwar ein Zeichen für emotionale Unordnung und damit Ausdruck von Laster, so kann Heiterkeit in Maßen durchaus legitim sein - mehr noch, ist spiritalis iocunditas das „Gegenmittel“ gegen acedia ${ }^{86}$. Ein wohl dosierter Scherz des Abtes - mal freundlicher, mal derber, je nach Konstitution des zu Belehrenden - führt zaudernde Novizen rasch wieder zurück auf den richtigen Weg (DM 4, 50f.). Lächelnd befragt ein konvertierter Ritter seinen einst aus Angst vor dem Ungeziefer im wollenen Klostergewand zaudernden Kollegen nach seinem Fortschritt auf dem letztlich doch gewählten spirituellen Weg (DM 4, 48). Ein Laienbruder erzählt auf einer Reise mit dem Kardinal von Albano eine erbauliche Parabel über die Konkurrenz eines Zisterziensers und eines Kardinals an den Pforten des Himmels, die nach dem Inhalt ihres Magens - Klosterkost oder opulente Speisen - entschieden wird; der Kardinal behält den Scherz lächelnd in Erinnerung, obwohl er auf seine Kosten ging (DM 4, 79). Ganz deutlich wird in allen Fällen, dass im Unterschied zu den dramatisch geschilderten "negativen“ Leidenschaften, den Versuchungen, die zur Sünde führen, und der ebenso leidenschaftlichen Angst vor deren Konsequenzen, der Großteil der referierten positiven Emotionen ebenso wie das entsprechende Vokabular - bilaris, iocundus, serenus - keines-

Christi corpus portat. Vgl. dazu Klaus SCHREINER, Consanguinitas - Verwandtschaft als Strukturprinzip religiöser Gemeinschafts- und Verfassungsbildung in Kirche und Mönchtum des Mittelalters, in: Beiträge zu Geschichte und Struktur der mittelalterlichen Germania Sacra, hg. von Irene Crusius (Göttingen 1989) 176-305. 82 DM lib. 4, c. 30, ebd. 742-753, hier 746/747: Stans enim extra chorum, et alios psallere audiens, quia intrare non licet, corde crucior, eo quod recorder consolationum, quibus Deus inter illos laerificat animam meam.

83 Ebd.: Confessus est ei, quia saepius in choro tempore psalmodiae beatos angelos videret circuire, et quod multo fuit excellentius, ipsum Regem angelorum hominem Christum Jesum.

${ }_{84}$ Vgl. oben Anm. 18. und 20.

85 DM lib. 4, c. 39, ebd. 766-771.

${ }_{86}$ Zu den Tugenden als "Gegenmitrel“ bzw. Waffen gegen die Laster vgl. DM lib. 4, c. 103, ebd. 944-947, hier 946/947. Zu dem auf der antiken Medizin (Hippokrates) beruhenden Prinzip des Gegenmittels vgl. z. B. Hieronymus, Epistolae, ep. 121, praef. 4, ed. Isidor HILBERG (CSEL 54-56, Wien ${ }^{2} 1996$ ) Bd. 3, 4: ... et iuxta hippocraten contraria contrariorum remedia. 
wegs überschwänglich, sondern gemäßigt, eben geordnet ist. Das rechte Maß zu halten, ohne aber gleichgültig - lau - zu werden, heißt eben, die innere und äußere Ordnung der Affekte zu bewahren bzw. (wieder) herzustellen, und das gilt sowohl für das Verhältnis von „innen" und „außen" beim jeweils einzelnen Menschen als auch für seinen Platz in der Gemeinschaft und in der ständischen Ordnung. Einfach, im Sinn von unmittelbar oder unreflektiert, ist dieses Emotionsmanagement allerdings weder in den frühmittelalterlichen monastischen Regeln noch in deren Anwendung auf die Praxis, sondern hoch differenziert und komplex - und eben zeitgebunden ${ }^{87}$.

Die von Caesarius in seinem Dialogus miraculorum angesprochenen Gemeinschaften sind sowohl seine reale unmittelbare Umgebung, die Klosterfamilie, als auch die Gemeinschaft seines Ordens, darüber hinaus geistlich, genauer monastisch lebender Menschen, und schließlich die Gemeinschaft aller Christen und Heiligen mit Gott. Diese Gemeinschaften sind in unterschiedlicher Intensität „emotional communities" im Sinn von Barbara Rosenwein, indem sie sich durch vergleichbare Formen von Bindung und Zugehörigkeit, durch gemeinsame Werte und Vorstellungen, ähnliche Formen von sozialer und spiritueller Praxis sowie durch gemeinsame Vorstellungen von Leidenschaften und emotionale Ausdrucksformen charakterisieren lassen ${ }^{88}$. Die emotionalen Repertoires, aus denen sich Caesarius' Geschichten bedienen, wurden offensichtlich zumindest teilweise auch gemeinschaftsübergreifend verwendet, und zwar nicht nur zwischen den bereits angesprochenen Gemeinschaften, sondern auch darüber hinaus, die „Welt" betref fend. Diese teilweise explizit angesprochene Nähe, die auch Fichtenau als Eigenschaft der Übergangsphase zum Spätmittelalter besonders betont, wird anhand der zahlreichen Bezüge zwischen Kloster und Welt mit ihren ebenfalls zahlreichen ambivalenten Wertungen und Übergangsformen, etwa der Stellung von Weltpriestern zwischen Ordensleuten und nicht enthaltsam lebenden Weltlichen deutlich. Besonders sichtbar werden sie anhand der wechselwirkenden Aspekte von geistlicher und weltlicher nobilitas, die zu superbia führen können, am Beispiel von Neid, Habsucht und Zorn, anhand derer Caesarius die Grenze zwischen Weltlichen und Geistlichen expliziert, und anhand der „körperlichen “ Sünden der Völlerei und der Unkeuschheit. Aber selbst zum typisch monastischen Sündenfeld der acedia bringt Caesarius Geschichten von weltlichen Personen, die sich aus Verzweiflung das Leben nehmen. Letztlich sind die Leidenschaften, die zu Lastern führen können, alle grundsätzlich sowohl für weltliche wie auch für geistliche Menschen gefährlich, wenn auch eben in unterschiedlichen Formen und in unterschiedlichem Ausmaß: spezifische Gemeinschaften schöpfen aus gemeinsamen emotionalen „Repertoires".

Gerade praktisch didaktisch motivierte und nicht zuletzt deshalb „populär" schreibende Seelsorger wie Caesarius waren offenbar eher geneigt, Ordnungsideale und asketische Disziplin der Affektkontrolle durch Gottesfurcht, Angst und Schrecken sowie durch das Prinzip des trauernden Buße-Tuns aufrechtzuerhalten und zu bekräftigen. Dies legt die verwendete Terminologie ebenso nahe wie die dramatischen Ausdrucksformen - eben wunderbare und erschreckende Inhalte und Inszenierungen vieler exempla. Dies dürfte

${ }^{87}$ Dazu die Arbeiten von Albrecht Diem, zulerzt etwa Disimpassioned Monks and Flying Nuns. Emotion Management in Early Medieval Rules, in: LuTTER, Funktionsräume (wie Anm. 41) 17-39; zur Historizitär von Emotionen in diesem Zusammenhang pointiert RosenweIn, Theories of Change (wie Anm. 3).

88 Ebd. 12 sowie 19 zu gleichzeitig existierenden "multiple emotional communities" sowie bereits DIES., Worrying (wie Anm. 34) 842 und 845. Vgl. auch Christina LuTter, Social Groups, Personal Relations, and the Making of Communities in Medieval vita monastica, in: Making Sense as Cultural Practice. Historical Perspectives, hg. von Jörg Rogge (Mainzer Historische Kulturwissenschaften 17, Bielefeld 2013) 45-61. gegenüber dem Publikum innerhalb der monastischen Gemeinschaften ebenso gelten wie für die zunehmende pastorale Praxis besonders der Mendikanten außerhalb. Das narrative Repertoire der exemplarischen Geschichten weist jedenfalls große Ähnlichkeiten auf, und wurde auch im Laufe des 13. Jahrhunderts verstärkt standardisiert ${ }^{89}$

Das emotionale Repertoire, das auf der zentralen Figur der Liebe beruht, ist selbstverständlich auch Caesarius von Heisterbach bekannt, doch die bräutliche Beziehung zwischen Gotr und dem individuellen Menschen ebenso wie die mystische Gabe des Schauens von Engeln und Christus selbst spielt nur in wenigen Geschichten eine Rolle und wird jeweils mit großer Vorsicht vor einem falschen "Gebrauch" durch weniger Geübte vorgetragen ${ }^{90}$. Bereits die Benediktregel sieht nur jene, die den zwölften Grad der Demut erreicht haben, dazu befähigt, die vorher ausgeführten Regeln der monastischen Disziplin, also mit Fichtenau die asketische Technik, gleichsam selbstverständlich und habituell in ihrem Herzen und mit ihrem Körper aus Liebe zu Gott und nicht aus Furcht vor der Hölle zu befolgen"1. Zwar spielt die "neue Frömmigkeit" mit einer privilegierten „Lie besbeziehung" zwischen Gott und der menschlichen Seele in den einschlägigen Texten des 12. und 13. Jahrhunderts klar eine zunehmend bedeutende Rolle. Dennoch stellt sich angesichts der insgesamt dramatisch anwachsenden pastoralen Überlieferung vor allem seit dem 13. Jahrhundert die Frage nach dem Publikum, das diese Vorstellungen und die mit ihnen verbundene spirituelle Praxis jeweils rezipierte und diskutierte.

Einerseits suggeriert eine Gegenüberstellung mit einem populären Werk der pastoralen Praxis wie dem Dialogus miraculorum eine eher zurückhaltende Rezeption. Andererseits waren viele der herausragenden monastischen Theoretiker dieser neuen Frömmigkeitsformen gleichzeitig auch pastorale Praktiker in unterschiedlichen Orden, wie etwa die Zisterzienser Bernhard von Clairvaux und Aelred von Rievaux, die Benediktiner Gottfried und Irimbert von Admont, der Dominikaner Thomas von Aquin und später Meister Eckhart, und nicht zuletzt Franziskus von Assisi. Aber auch bei ihnen wird das Individuum nicht gegen, sondern in konstanter Wechselwirkung mit der Gemeinschaft gedacht und angesprochen ${ }^{22}$. Auch die Zunahme des „neuen Frömmigkeitsstils“ in der an nicht gelehrte Menschen gerichteten pastoralen Didaxe ist offensichtlich. Die Grenzen zwischen theologisch gelehrten und praktisch pastoralen Diskursen und den jeweils ange-

89 Zur Entwicklung zisterziensischer exempla als Genus vgl. die gesammelten Aufsäze von Brian P. McGuire, Friendship and Faith (wie Anm. 40). Zu Gründen und Zielen einer "popular pedagogy" am Beginn des 13. Jahrhunderts am Beispiel des Dominikaners William Peraldus vgl. NewHauser, Vices as Anthropology (wie Anm. 12) 119-121.

90 DM lib. 4, c. 30 (wie Anm. 4) 742-753: Christian vom St. Peterstal als Braut Christi; DM lib. 4, c 39, ebd. 766-771: Visionen der verzweifelnden Rekluse; DM lib. 4, c. 80, ebd. 876/877: Süßigkeit der Seitenwunde Christi.

${ }^{9}$ Vgl. RB c. 7 (wie Anm. 12) hier 41 sowie 50-52: ... Primus itaque humilitatis gradus est, si timorem Dei sibi ante oculos semper ponens, oblivionem omnino fugiat et semper sit memor omnia quae praecepit Deus, ut qualiter et contemnentes Deum gehenna de peccatis incendat et vita aeterna quae timentibus Deum praeparata est, animo sto semper revolvat. [...] Duodecimus humilitatis gradus est, si non solum corde monachus, sed etiam ipso corpore humilitatem videntibus se semper indicet, [...] Ergo, his omnibus humilitatis gradibus ascensis, monachus mox ad caritatem Dei perveniet illam quae perfecta foris mittit timorem, per quam universa quae prius non sine formidine observaba absque ullo labore velut naturaliter ex consuetudine incipiet custodire, non iam timore gehennae, sed amore Christi consuetudine ipsa bona et dilectatione virturum. Quae Dominus iam in operarium suum mundum a vitis at peccas Spiritu Sancto dignabitur demonstrare. Vgl. dazu v. a. Bernhard von Clairvaux, Liber de gradibus humilitaris et superbiae (wie Anm. 62)

92 Dazu BoQuer, L'ordre de l'affect (wie Anm. 19); aktuelle Übersicht der einschlägigen Literatur bei Rosenwein, Theories of Change (wie Anm. 3), bes. $17 \mathrm{f}$ 
sprochenen Publikumsgruppen sind meist fließend und verlaufen nicht entlang eindeutig zu identifizierender Achsen ${ }^{93}$. Ein Charakteristikum dieser Zeit dürfte nicht zuletzt das Vorhandensein unterschiedlicher emotionaler Repertoires neben einander gewesen zu sein, die sowohl für die affektiven Bindungen in geistlichen Gemeinschaften eine Rolle gespielt haben wie auch in den als individuell beschriebenen Beziehungen der Menschen zu Gott. Inwieweit diese Modelle in Konkurrenz zu einander standen und in welchem $\mathrm{Maß}$ sie integriert wurden, ob diese Gemeinschaften in und zunehmend auch außerhalb des monastischen Raums als distinkte emotionale Gemeinschaften beschrieben werden können, darüber wissen wir noch vergleichsweise wenig. Das im Spätmittelalter reichlich vorhandene Quellenmaterial und das methodische Handwerkszeug einer an Gefühlen und ihren Representationen interessierten Kulturgeschichte, die sich mit Fichtenau dem Menschen als Ganzes annähern will und dabei gleichzeitig die Vielfalt, Gleichzeitigkeit und Ambivalenz historischer Phänomene ernst nimmt, versprechen neue Antworten auf diese Frage.

93 Vgl. z. B. Laienfrömmigkeit im späten Mittelalter. Formen, Funktionen, politisch-soziale Zusammenhänge, hg. von Klaus Schreiner (München 1992); Ruн, Mystik (wie Anm. 20). Zum lezten Punkt v. a. Bynum, Christian Materiality (wie Anm. 9) $129 f$.

\section{Siglenverzeichnis}

Abhandlung(en) (allgemein)

Allgemeine Deutsche Biographie

Archiv der Republik

Archiv für Diplomatik, Schriftgeschichte, Siegel- und Wappenkunde

Archiv für Kulturgeschichte

Annuarium Historiae Conciliorum

Annales Économies, Sociétés, Civilisations

Archiv für Österreichische Geschichte (bis Bd. 33: für Kunde österreichischer Geschichts-Quellen)

Archivio della Società Romana di Storia Patria

Archivio Segreto Vaticano

Archiv für Urkundenforschung

Archivalische Zeitschrift

Biblioteca Apostolica Vaticana

Bibliothek des Deutschen Historischen Instituts in Rom

Bibliothèque de l'École des chartes

Bullettino dell'Istituto Storico Italiano per il Medio Evo (e Archivio Mu ratoriano)

Blätter des Vereins für Landeskunde von Niederösterreich

Bibliothèque Nationale

Urkundenbuch zur Geschichte der Babenberger in Österreich

Corpus Christianorum. Series Latina

Clavis Patristica Pseudepigraphorum Medii Aevi

Corpus Scriptorum Ecclesiasticorum Latinorum

Deutsches Archiv für Erforschung (bis 1944: Geschichte) des Mittelalters English Historical Review

Frühmittelalterliche Studien

Fontes Rerum Austriacarum

Fonti per la Storia d'Italia

Haus-, Hof- und Staatsarchiv

Historisches Jabrbuch

Handwörterbuch zur deutschen Rechtsgeschichte

Historische Zeitschrift

Institut für Österreichische Geschichtsforschung

Jabrbuch für Landeskunde von Niederösterreich

Jahrbuch des oberösterreichischen Musealvereins - Gesellschaft für Landeskunde

JAFFÉ-LöWEnfeld, Regesta Pontificum Romanorum

Lexikon des Mittelalters 
Johannes Dominicus MANSI, Sacrorum conciliorum nova et amplissima collectio. Florenz-Venedig 1757-1798 (Nachdr. Graz 1960-

MGH 1961)

Monumenta Germaniae Historica

AA Auctores antiquissimi

D, DD Diploma, Diplomata

LL Leges

SS Scriptores

(die weiteren Reihen in verständlichen Kürzungen)

MIÖG (MÖIG) Mitteilungen des Instituts für Österreichische Geschichtsforschung (19231942: des Öterreichischen Instituts für Geschichtsforschung, 1944: des Instituts für Geschichtsforschung und Archivwissenschaft in Wien)

$M O ̈ O L A$

MOStA

$N A$

NOLA

ÖAW

ÖNB

ÖStA

PL

POTTHAST

QEBG

QFIAB

QIÖG

Reg. Imp.

$R G A$

RH

$R H E$

$\mathrm{SB}$

SC

Settimane

St $T$

$U H$

VIÖG

$V L^{2}$

VSWG

$\mathrm{VuF}$

$Z B L G$

$Z f d P h$

ZHVSt

Mitteilungen des Oberösterreichischen Landesarchivs

Mitteilungen des Österreichischen Staatsarchivs

Neues Archiv der Gesellschaft für ältere deutsche Geschichtskunde

Mitteilungen aus dem Niederösterreichischen Landesarchiv

Österreichische Akademie der Wissenschaften

Österreichische Nationalbibliothek

Österreichisches Staatsarchiv

Migne, Patrologia Latina

Potrthast, Regesta Pontificum

Quellen und Erörterungen zur Bayerischen Geschichte

Quellen und Forschungen aus italienischen Archiven und Bibliotheken

Quelleneditionen des Instituts für Österreichische Geschichtsforschung

Regesta Imperi

Reallexikon der Germanischen Altertumskunde

Revue Historique

Revue d'Histoire Ecclésiastique

Sitzungsberichte (allgemein)

Sources Chrétiennes

Settimane di Studio del Centro Italiano sull'Alto Medioevo

Studi e Testi

Unsere Heimat. Zeitschrift für Landeskunde von Niederösterreich

Veröffentlichungen des Instituts für Österreichische Geschichtsfor-

schung

Die deutsche Literatur des Mittelalters. Verfasserlexikon (2. Auflage)

Vierteljahrschrift für Sozial- und Wirtschaftsgeschichte

Vorträge und Forschungen

Zeitschrift für bayerische Landesgeschichte

Zeitschrift für deutsche Philologie

Zeitschrift des Historischen Vereins für Steiermark 